\title{
Description des rhyncholites des Nautiles (Mollusca, Cephalopoda) du Paléogène des bassins de Paris et d'Aquitaine et des Corbières (France)
}

\author{
Jean-Michel PACAUD \\ Muséum national d'Histoire naturelle, Département Histoire de la Terre, \\ UMR 7207 du CNRS, CR2P, \\ case postale 38, 57 rue Cuvier, F-75231 Paris cedex 05 (France) \\ pacaud@mnhn.fr
}

MOTS CLÉS

Rhyncholite, Mollusca,

Cephalopoda, Crétacé superieur,

Eocène,

Oligocène,

France,

Europe,

combinaison nouvelle, espèces nouvelles.
Pacaud J.-M. 2010. - Description des rhyncholites des Nautiles (Mollusca, Cephalopoda) du Paléogène des bassins de Paris et d'Aquitaine et des Corbières (France). Geodiversitas 32 (1): 121-156.

\section{RÉSUMÉ}

Des rhyncholites sont signalés pour la première fois au Paléogène des bassins de Paris et d'Aquitaine et des Corbières (France). L'étude d'une trentaine de spécimens permet d'identifier 11 espèces attribuées au genre Rhyncolites Biguet, 1819: Rhyncolites guanensis n. sp. de l'Yprésien (Cuisien, Éocène inférieur) du Béarn; R. shinfieldensis Ward \& Cooper, 1972, R. aethioparion Ward \& Cooper, 1972, $R$. corbaricus $\mathrm{n}$. sp., $R$. foncouvertensis $\mathrm{n}$. sp. et $R$. martinezi n. sp. de l'Yprésien (Ilerdien, Éocène inférieur) des Corbières; $R$. vilcassinus n. sp., $R$. sagittarius n. sp. et $R$. lhommei n. sp. du Lutétien (Éocène moyen) du Bassin de Paris et $R$. aturensis n. sp. du Chattien (Oligocène supérieur) des Landes. Ce travail est aussi l'occasion de décrire une espèce du Thanétien (Paléocène supérieur) d'Espagne, R. erroitegiensis $\mathrm{n}$. sp. Le rhyncholite Rhynchoteuthis dutemplei d'Orbigny, 1847 du Campanien (Crétacé supérieur) de Chavot (Marne) avait été perdu par d'Orbigny avant qu'il puisse en donner une description détaillée et des figures. L'holotype par monotypie, validée par une simple indication, a été retrouvé dans la collection d'Orbigny. Nous donnons une description et une figuration de cette espèce que nous assignons au genre Rhyncolites.

\footnotetext{
ABSTRACT

Description of the rhyncholites of Nautiloid (Mollusca, Cephalopoda) from the Paleogene of the Paris and Aquitaine basins and Corbières (France).

Rhyncholites are reported for the first time in the Paleogene of Paris and Aquitaine basins and Corbières (France). The study of around 30 specimens allows to identify 11 species attributed to the genus Rhyncolites Biguet, 1819: Rhyncolites guanensis n. sp. from Ypresian (Cuisian, lower Eocene), R. shinfieldensis Ward \& Cooper, 1972, R. aethioparion Ward \& Cooper, 1972, R. corbaricus n. sp.,
} 


\author{
KEY WORDS \\ Rhyncholite, \\ Mollusca, \\ Cephalopoda, \\ Late Cretaceous, \\ Eocene, \\ Oligocene, \\ France, \\ Europe, \\ new combination, \\ new species.
}

$R$. foncouvertensis n. sp. and R. martinezi n. sp. from Ypresian (Ilerdian, lower Eocene), $R$. vilcassinus n. sp., $R$. sagittarius n. sp. and $R$. lhommei n. sp. from the Lutetian (middle Eocene) of the Paris basin and $R$. aturensis n. sp. from the Chattian (upper Oligocene). This work is also the occasion to describe a species from the Thanetian (late Paleocene) of Spain, R. erroitegiensis n. sp. The rhyncholite Rhynchoteuthis dutemplei d'Orbigny, 1847 from the Campanian (upper Cretaceous) from Chavot (Marne) had been lost by d'Orbigny before he can give a detailed description and figures. The holotype by monotypy, validated by a simple indication, was found in the d'Orbigny collection. We give a description and figures of this species which we assign to the genus Rhyncolites.

\section{INTRODUCTION}

Le rhyncholite désigne l'épaississement local calcifié de la paroi essentiellement conchyolinitique de la mandibule des céphalopodes. Les Nautiles (Fig. 1A-E), Céphalopodes tetradibranchiaux, sont les seuls actuellement pouvant sécréter un élément calcaire à la mâchoire (Griffin 1900; Dean 1901; Willey 1902; Okutani \& Mikami 1977); les mandibules des Céphalopodes dibranchiaux tels que les Octopoda, les Sepioidea et les Theutoidea sont entièrement composées de chitine (Mangold \& Fioroni 1966; Müller 1974; Clarke 1986; Kanie 1998) (Fig. 1F, G), à l'exception de celles du genre Sepia Linnaeus, 1758 qui possèdent une fine couche d'aragonite (moins de $100 \mu \mathrm{m}$ d'épaisseur) (Tanabe et al. 1980). Biguet (1819) introduisit le terme vernaculaire Rhyncholite pour l'élément calcaire de la mandibule supérieure des céphalopodes, l'épaississement local calcifié de la mandibule inférieure étant dénommée par de Blainville (1827) conchorhynchus. Les rhyncholites sont composés presque exclusivement de cristaux prismatiques de calcite (Septfontaine 1970). Les conchorhynchus, eux, sont composés d'un revêtement de calcite autour de la substance cornée (Teichert et al. 1964) et sont beaucoup moins robustes; ce qui explique probablement leur excessive rareté dans les sédiments paléogènes où nous n'en connaissons que de rares spécimens. Les rhyncholites sont connus dans la littérature paléontologique depuis très longtemps. Ils ont été considérés par certains auteurs comme des becs d'oiseaux ou de cirripèdes (von Schlotheim 1820). Du fait de leur similarité avec les mandibules de Sepia ou d'autres céphalopodes actuels Gaillardot (1824) leur reconnaît un lien de parenté; Biguet (1819) introduit le genre Rhyncolites et les rapporte aux Belemnoides. D’Orbigny (1825a, b; 1826) est le premier à suggérer que les «becs à capuchon» appartiennent aux Nautiles. Il a d'autant plus de mérite, qu'en 1825 l'appareil buccal des Nautiles actuels n'a encore été ni prélevé ni étudié. Sa clairvoyance sur ce sujet s'avérera confirmée quelques années après (Owen 1832) par l'étude de l'animal du Nautilus pompilius Linnaeus, 1758. Ceci étant, il semble que les Nautiles ne soient pas les seuls céphalopodes possédant des rhyncholites et des conchorhynchus aux mâchoires. Les ammonites Tetragonites glabrus (Jimbo in Yabe, 1903), Gaudryceras tenuiliratum Yabe, 1903, G. denseplicatum (Jimbo, 1894), Neophylloceras subramosum Spath, 1939, Zelandites inflatus Matsumoto, 1959 et Phyllopachyceras ezoense Yokoyama, 1890 du Crétacé du Japon et de Russie possèdent en effet des éléments calcaires aux mandibules supérieure et inférieure (Schmidt-Effing 1972; Kanie et al. 1978; Tanabe et al. 1980 ; Nixon 1996). Leur forme et leur structure, différentes des Aptychi et Anaptychi, sont similaires non seulement aux rhyncholites et aux conchorhynchus des Nautiles actuels mais aussi à ceux des formes fossiles du Mésozoïque et du Cénozoïque. Ces éléments calcifiés de la mandibule de ces ammonites ont depuis reçu le nom de Rhynchaptychus (Lehmann et al. 1980). 


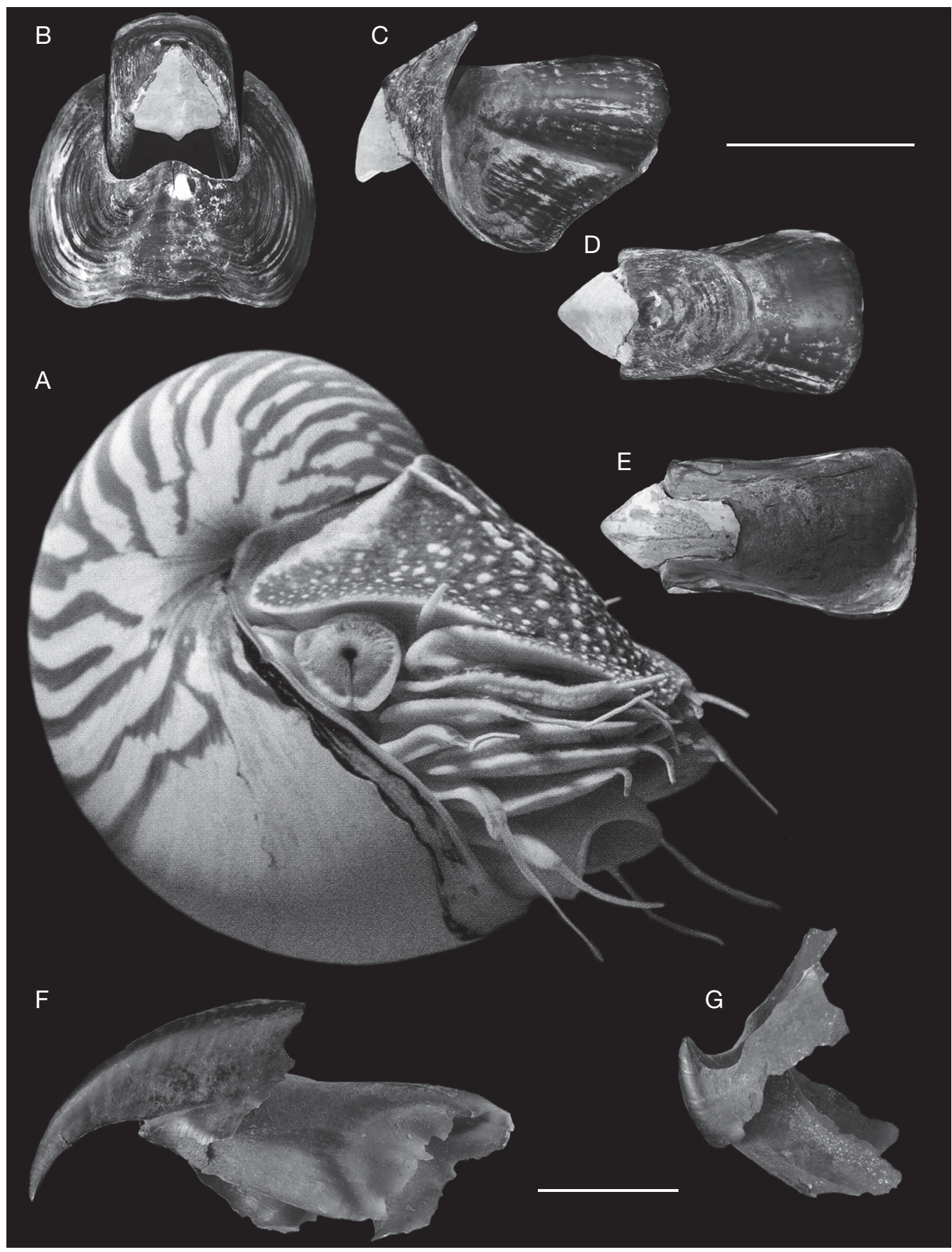

FIG. 1. - A, Nautilus pompilius Linnaeus, 1758 nageant (C Lanceau-Labat/Aquarium La Rochelle); B-E, mandibules de Nautile actuel (espèce non déterminée) (MNHN-Céphalopodes, $n^{\circ}$ 1.2.21). Le rhyncholite est composé de calcite, les autres parties de la mandibule sont composées de chitine; B, vue de face des mandibules supérieure et inférieure; C, vue latérale; D, vue dorsale; E, vue ventrale de la mandibule supérieure; F, G, mandibules typiques de Céphalopodes dibranchiaux représentées par Loligo vulgaris Lamarck, 1798, composées uniquement de chitine. Boulogne-sur-Mer (Pas-de-Calais, France) (MNHN A27256, coll. d'Orbigny). Échelles: 10 mm. 
Suite aux publications de Till $(1906 ; 1907 ; 1909$; 1910 ; 1911), les données sur les rhyncholites furent révisées mais leur évolution et leur intérêt stratigraphique n'ont pu être étudiés du fait des mensurations et des informations stratigraphiques très imprécises (Gasiorowski 1973a). Bien que les fossiles de céphalopodes soient très rares au Cénozoïque, des Nautiles appartenant aux genres Hercoglossa Conrad, 1866, Eutrephoceras Hyatt, 1894, Angulithes de Montfort, 1808 et Aturoidea Vredenburg, 1925 sont signalés au Paléogène du Bassin de Paris, Cimomia Conrad, 1866 et Deltoidonautilus Spath, 1927 à l'Yprésien des Corbières, Aturia Brown, 1838 et Cimomia (Merle comm. pers.) à l'Yprésien du Béarn et Aturia au Rupélien d'Aquitaine. Toutefois, plusieurs rhyncholites ont été récoltés à l'Éocène et à l'Oligocène des bassins de Paris, d'Aquitaine et des Corbières, mais aucun n'avait été décrit et discuté jusqu'ici. Seuls Doncieux (1908) dans son étude des fossiles des Corbières et Merle (1986) dans son mémoire sur l'Yprésien de Gan (Pyrénées-Atlantiques) en signalaient la présence. À noter également dans le travail d'Hébert (1855: 369, pl. 29, fig. 1) le signalement de rhyncholites (Campanien) à Meudon (Hauts-de-Seine).

Les rhyncholites sont classés en deux groupes principaux: les Rhynchoteuthis d'Orbigny, 1847 (espèce type Rhynchoteuthis astierianus d'Orbigny, 1847 par désignation subséquente), exclusivement fossiles et les rhyncholites sensu stricto, se poursuivant jusqu'à nos jours. Les Rhynchotheuthis (= Hadrocheilus Till, 1907, espèce type Hadrocheilus theodosa Till, 1907 par désignation subséquente) disparaissent au Crétacé supérieur avec des espèces des sousgenres Rhynchoteuthis sensu stricto et Arcuatobeccus Shimansky, 1947 (espèce type Hadrocheilus procerus Till, 1907 par désignation originale) devenus très rares. Les céphalopodes à rhyncholites étaient des Nautilidae et en partie, comme nous venons de le souligner, des Ammonoidea; quant aux céphalopodes à Rhynchoteuthis, des reconstitutions ne sont pas possibles. En effet comme l'écrit Gasiorowsky (1973a), on ne connaît aucun céphalopode qui peut lui être attribué. Les musculatures buccales semblent différentes de celles des Nautilidae et des autres céphalopodes, car la mandibule supérieure est tripartite et non pas unipartite telle que celle de Rhyncolites. Il est probable que les Rhynchoteuthis appartiennent à un groupe de Céphalopodes sans coquille dont il ne resterait que ces éléments calcaires. Les mandibules des Nautiles actuels sont beaucoup plus développées que celles de tous les autres céphalopodes. Clarke (1962) montre ainsi que la mandibule d'un Architeuthis géant pesant plus d'une tonne ne mesurait guère plus d' $1 \mathrm{~cm}$; dimension largement atteinte chez un Nautile ne pesant pas plus de $500 \mathrm{~g}$. Le plus grand spécimen récolté jusqu'ici (Crick 1916), un rhyncholite écrasant, Rhyncolites butleri (Crick, 1916) du Jurassique d'Angleterre, mesure 51,7 $\mathrm{mm}$ de long.

\section{DISTRIBUTION DES RHYNCHOLITES}

Les rhyncholites sont récoltés sur tous les continents hormis l'Australie et l'Antarctique. Les plus anciens becs de mandibule supérieure de céphalopodes ont été décrits du Pennsylvanien (Silésien, Carbonifere supérieur) d'Uruguay (Closs 1967) représentés par des mandibules du Goniatite Eosianites Ruzencev, 1933 et du Guadalupien (Capitanien, Permien) de Russie (Zakharov \& Lominadze 1983) représentés par des mandibules du Coleoide Permorhynchus Zakharov, 1983. Le genre Rhyncolites Biguet, 1819 est indubitablement connu depuis le Trias avec $R$. hirundo Biguet, 1819 et $R$. cassianus Till, 1906. Du Trias au Crétacé supérieur les céphalopodes à rhyncholites ont vécu dans des eaux peu profondes. Au Paléogène ils se sont déplacés vers des eaux plus profondes (Éocène de Transylvanie et d'Aquitaine) mais toujours près des zones côtières (Gasiorowski 1973a). Alors que les céphalopodes montrent un développement considérable au Mésozoïque, les fossiles sont au contraire excessivement rares au Cénozoïque. Seules six espèces de Nautile, Eutrephoceras umbilicare (Deshayes, 1835), E. parisiense (Deshayes, 1865), Angulithes disculus (Deshayes, 1865), A. calvimontensis (Bédé, 1948), A. lamarckii (Deshayes, 1835) et Aturoidea ziczac (Sowerby, 1812) ont par exemple été décrites de l'Éocène du Bassin de Paris (Pacaud \& Le Renard 1996; Pacaud 2008) (Figs 13; 14). De fait les découvertes de rhyncholites sont peu nombreuses. Dans le Tableau 1 nous donnons les informations sur la distribution de toutes les espèces de Rhyncolites connus. 
Plusieurs rhyncholites de Nautiles ont été reconnus au Paléogène:

- Rhyncolites sp. Vincent 1901 du Lutétien (Laekenien, Éocène moyen) de Belgique (= Rhyncholites cf. shinfieldensis sensu Le Renard \& Pacaud 1995 non Ward \& Cooper 1972);

- R. oppenheimi Till, 1911 (= Rhyncolithes sp. Oppenheim 1906) de l'Éocène de Wadi (Mokattam, Egypte);

- R. sp. Teichert \& Stanley 1975 de l'Éocène d'Ardath Shale (Californie);

- R. albestii Popescu Voiteşti, 1910 (Popescu Voiteşti 1910: 97, 98, pl. 22, fig. 13; $R$. albestii Till, 1911 est un synonyme objectif plus récent) un rhyncholite écrasant du Lutétien (Éocène moyen) de Albeşti (Roumanie), espèce rapportée à tort par Gasiorowski (1973b) à Acutobeccus (forme de rhyncholite servant essentiellement à percer les proies);

- Acutobeccus sp. Şuraru 1963 et $R$. voitestii Şuraru, 1963 de la même région;

- Acutobeccus evansi Teichert \& Spinosa, 1971, un rhyncholite perçant du Priabonien (Shubuta Member, Yazoo Clay, Jackson Group, Éocène supérieur) de Clarke County (Mississippi);

- R. aethioparion Ward \& Cooper, 1972 et $R$. shinfieldensis Ward \& Cooper, 1972, deux rhyncholites écrasants de l'Yprésien (London Clay, Éocène inférieur) d'Angleterre;

- R. sp. Élouard 1962 de l'Éocène de Mauritanie (Afrique);

- R. sp. Merle 1986 (décrit ici sous le nom de $R$. guanensis n. sp.) de l'Yprésien (Cuisien, Éocène inférieur) de Gan (Pyrénées-Atlantiques).

Au Néogène plusieurs taxons ont également été décrits par Bellardi (1873) et par Sacco (1904):

- $R$. allionii Bellardi, 1873, $R$. suballionii Sacco, $1904, R$. rosavendae Sacco, 1904, $R$. paronae Sacco, 1904, R. formae Sacco, 1904, R. eogassinensis Sacco, 1904 du Miocène du Piémont (Italie);

- Scaptorhynchus miocenicus Bellardi, 1873, une forme perçante, du Miocène du Piémont (Italie), du Vaucluse et du Var (France);

- Scaptorhynchus sp. Philippe \& Granier $1981 \mathrm{du}$ Miocène d'Avignon (Vaucluse, France);

-R. mediterraneus Till, 1907 (= R. sp. Foord, 1891), une forme proche d'Acutobeccus, du Miocène de Malte;
Tableau 1. - Distribution géographique et stratigraphique du genre Rhyncolites Biguet, 1819.

\begin{tabular}{|c|c|c|c|c|}
\hline \multirow[b]{2}{*}{ Alpes } & Trias & \multicolumn{3}{|c|}{ Jurassique Crétacé Cénozoïque } \\
\hline & $\mathbf{\Delta}$ & $\boldsymbol{\Delta}$ & $\Delta$ & \\
\hline Allemagne & $\boldsymbol{\Delta}$ & $\boldsymbol{\Delta}$ & & \\
\hline Pays-Bas & & & $\boldsymbol{\Delta}$ & \\
\hline Malte & & & & $\Delta$ \\
\hline Italie & & & & $\boldsymbol{\Delta}$ \\
\hline France & $\boldsymbol{\Delta}$ & $\boldsymbol{\Delta}$ & $\Delta$ & $\boldsymbol{\Delta}$ \\
\hline Belgique & & & & $\boldsymbol{\Delta}$ \\
\hline Angleterre & & $\boldsymbol{\Delta}$ & $\Delta$ & $\boldsymbol{\Delta}$ \\
\hline Pologne & & $\boldsymbol{\Delta}$ & $\Delta$ & \\
\hline Roumanie & & & $\Delta$ & $\boldsymbol{\Delta}$ \\
\hline Tchécoslovaquie & & & $\Delta$ & \\
\hline Crimée & & & $\Delta$ & \\
\hline Bassin de & & & $\Delta$ & \\
\hline Donetz & & & & \\
\hline Syrie & & & & $\boldsymbol{\Delta}$ \\
\hline Égypte & & & & $\Delta$ \\
\hline Mauritanie & & & & $\Delta$ \\
\hline Mississippi & & & & $\Delta$ \\
\hline Californie & & & & $\boldsymbol{\Delta}$ \\
\hline
\end{tabular}

- Rhynchotheuthis [sic] sp. Lossel 1947 du Miocène du Maroc (Afrique);

- R. sp. Gasiorowski 1968 du Miocène de Roumanie;

- R. sp. Gasiorowski 1968 du Miocène de Syrie (Asie).

Belosepia minutissima Dom Valette, 1925 (Dom Valette 1925: 206, 207) du Burdigalien de Pont-Pourquey, Saucats (Gironde) et du Serravalien de Debat, Salles et de Lalande, Mios (Gironde) que Peyrot (1932) classe dans le genre Rhyncolites et qu'il rapporte comme la mandibule de Aturoidea aturi (Basterot, 1825) n'est pas un prolongement calcifié d'une mandibule mais représente plutôt la partie rostre/phragmocône d'un Céphalopode coleoide.

\section{RAPPEL ANATOMIQUE}

Les mandibules conchyolinitiques du Nautile sont composées d'une partie interne et externe; des muscles buccaux puissants s'insèrent dans le plissement formé par ces deux parties. L'extrémité antérieure de la mandibule supérieure s'allonge en un rostre aigu, remplacé par une dent calcaire, le rhyncholite (Fig. 1B-E). La croissance du rhyn- 
cholite se déroule en deux temps. En premier lieu, la surface mordante est recouverte par l'organe sécrétant la calcite, le rhyncholite ne représente alors qu'un renforcement interne du palais de la bouche du Nautile. Puis l'organe sécrétant la calcite rétrécit et disparaît ; le rhyncholite cesse de croître, émerge et devient une dent (Gasiorowski 1973a). Les céphalopodes vivants semblent atteindre leur maturité l'année suivant la naissance (Mangold 1966) ; l'appareil buccal est déjà formé. Ce n'est pas le cas chez Nautilus (Landman \& Cochran 1987) qui peut vivre une vingtaine d'années. Il semble que le rhyncholite ne soit pas présent dès l'incubation mais on ne le connaît pas encore chez les spécimens népioniques (Landman comm. pers.). La croissance du rhyncholite paraît avoir eu un terme bien défini même si l'animal croissait encore (Gasiorowski 1973a). Sa morphologie générale est demeurée remarquablement stable depuis le Trias (Kaiser \& Lehmann 1971; Klug 2001). Saunders et al. (1978: pl. 10) en montrent parfaitement l'exemple en donnant des figures du rhyncholite de l'actuel Nautilus pompilius, du rhyncholite de Syrionautilus libanoticus (Foord \& Crick, 1890) du Crétacé supérieur du Liban et du Rhyncolites hirundo Biguet, 1819 du Trias qui ne présentent guère de différence. La taille relative de la hampe est un caractère important au point de vue fonctionnel. C'est par la hampe que le rhyncholite se rattache à la partie conchyolinitique de la mandibule. Sa fixation, plus ou moins solide, détermine la force plus ou moins grande du rhyncholite. Les spécimens décrits ci-après, ont pour la plupart une hampe plus petite, bien dégagée du capuchon.

La partie antérieure du capuchon avec un apex aigu est destinée à percer la proie, les bords latéroantérieurs tranchants sont destinés à la couper. Les concavités s'étendant le long des bords latéro-antérieurs servent à assurer le maintien de la prise et l'arête médiane sur la face ventrale du rhyncholite sert à écraser la proie (Fig. 2F, G). Sur la surface mordante de plusieurs rhyncholites appartenant au Nautilidae les concavités le long des bords latéroantérieurs sont recouvertes de petits sillons. Leur fonction serait d'améliorer la prise de la nourriture. De tels sillons n'ont pu être observés que chez deux espèces paléogènes. La quasi totalité des rhyncholites du Cénozoïque des Bassins de Paris, d'Aquitaine et des Corbières possède une surface mordante présentant une arête médiane large et saillante exprimant des formes servant surtout à écraser les proies. Une seule de ces espèces présente au contraire une adaptation extrême au déchirement des proies (Fig. 9D-F). Certains spécimens montrent sur la face ventrale, de part et d'autre de l'arête médiane, de nombreux sillons qui varient en longueur et espacement (Fig. 4E, K).

\section{TERMINOLOGIE ET MENSURATIONS}

Les rhyncholites sont constitués de deux parties désignées sous les noms de capuchon et de hampe. Le capuchon est antérieur, bien développé, avec un apex plus ou moins aigu et fixé à l'arrière à une hampe de dimension plus faible. La terminologie descriptive et les mensurations employées (Fig. 2A-E) pour les rhyncholites sont celles utilisées par Teichert et al. (1964), Houša (1969) et Teichert \& Spinosa (1971).

\section{CADRE GÉOGRAPHIQUE ET STRATIGRAPHIQUE}

Le présent travail est consacré à l'étude des Rhyncholites du Paléogène français. Il s'agit de spécimens de l'Yprésien (Ilerdien et Cuisien), du Lutétien inférieur et moyen et du Chattien. Nous n'avons pu observer aucun spécimen de Rhyncholites du Danien et du Bartonien où des fossiles de Nautiles sont néanmoins décrits. En annexe seront traités des spécimens du Campanien de la Marne (France) et du Thanétien d'Espagne. Les sites du Paléogène français mentionnés se répartissent dans quatre secteurs principaux:

- d'une part, dans le Bassin de Paris, dans le département de l'Eure, à l'est d'Évreux (Le Bois du But à Fontenay-en-Vexin et à Breuil), dans le département de l'Oise, au sud de Beauvais, à Chaumont-en-Vexin et à Cauvigny) et dans le département du Val d'Oise, au nord de Pontoise (Les Garennes à Chaussy et à Champagne-surOise) ; 

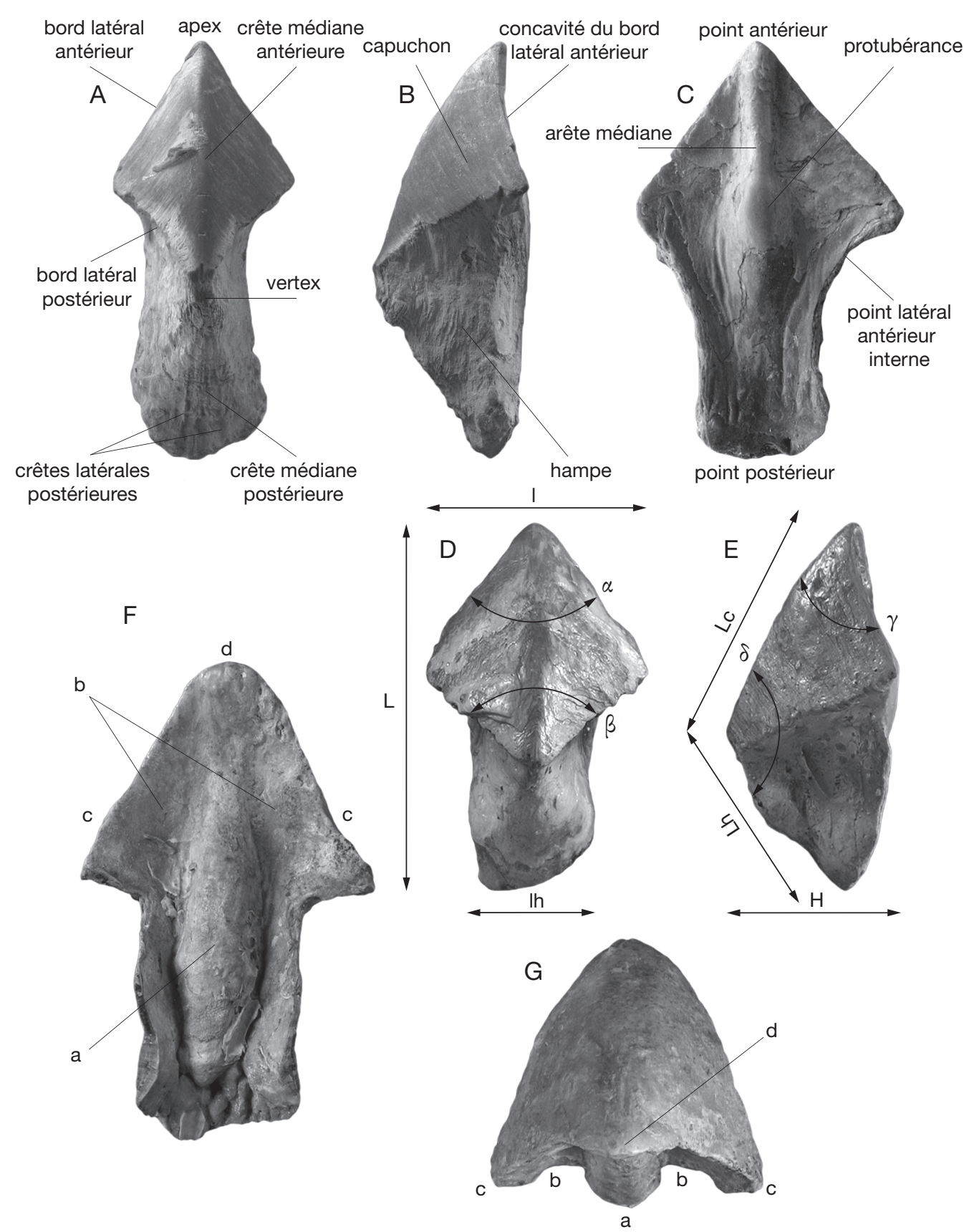

FIG. 2. - Terminologie, mensurations et orientation des rhyncholites: A, D, vues dorsales; B, E, vues latérales; C, F, vues ventrales; G, vue apicale; F, G, surface mordante montrée chez une des plus grandes espèces, Rhyncolites giganteus d'Orbigny, 1825 du Jurassique de la Pointe du Chay, Angoulins (Charentes, France), MNHN R07568 (coll. d'Orbigny). Abréviations: $\mathbf{a}$, arête médiane convexe; $\mathbf{b}$, parties latérales concaves; c, bords latéro-antérieurs tranchants; d, extrémité antérieure pointue; H, hauteur; L, longueur totale; I, largeur; Ih, largeur de la hampe; Lh, longueur de la hampe; Lc, longueur du capuchon; $\alpha$, angle apical en vue dorsale; $\beta$, angle de la partie postérieure du capuchon; $\gamma$, angle apical en vue latérale; $\delta$, angle du vertex. 
Tableau 2. - Dimensions (en mm) des Rhyncolites Biguet, 1819 discutés dans le texte. Abréviations: L, longueur totale; I, largeur.

\begin{tabular}{lccll}
\hline & L & I & Localité & Âge \\
\hline Rhyncolites americanus Teichert \& Spinosa, 1971 & 20,5 & 13,8 & Californie & Maastrichtien \\
Rhyncolites dutemplei (d'Orbigny, 1847) & 20,5 & 13,8 & France & Campanien \\
Rhyncolites erroitegiensis n. sp. & 17 & 12,5 & Espagne & Thanétien \\
Rhyncolites martinezi n. sp. & 3,3 & 2,1 & France & Ilerdien \\
Rhyncolites corbaricus n. sp. & 21,2 & 11 & France & Ilerdien \\
Rhyncolites foncouvertensis n. sp. & 15,4 & 8,2 & France & Ilerdien \\
Rhyncolites aethioparion Ward \& Cooper, 1972 & 8,3 & 5 & Angleterre & Yprésien \\
Rhyncolites shinfieldensis Ward \& Cooper, 1972 & 7 & 5,9 & Angleterre & Yprésien \\
Rhyncolites guanensis n. sp. & 27 & 15,1 & France & Cuisien \\
Rhyncolites albestii Popescu Voiteşti, 1910 & 43 & 20 & Roumanie & Lutétien \\
Rhyncolites vilcassinus n. sp. & 18,5 & 11 & France & Lutétien \\
Rhyncolites sagittarius n. sp. & 18,5 & 11 & France & Lutétien \\
Rhyncolites Ihommei n. sp. & 7,9 & 5,2 & France & Lutétien \\
Rhyncolites sp. - Vincent 1901 & 20,2 & 11,7 & Belgique & Lutétien \\
Rhyncolites oppenheimi - Till 1911 & 44 & 23 & Égypte & Eocène sup. \\
Rhyncolites sp. - Teichert \& Stanley 1973 & 20,5 & 13,8 & Californie & Eocène moy. \\
Rhyncolites aturensis n. sp. & 12,4 & 7,1 & France & Chattien \\
\hline
\end{tabular}

- d'autre part, dans le Bassin d'Aquitaine, dans le département des Landes, dans la région de l'Adour, près de la commune de Saint-Paul-lès-Dax (Abesse);

- dans les Corbières, dans le département de l'Aude, au sud de Carcassonne et de Narbonne (Requy à Montlaur; Montauriol à Servies-en-Val; Lavade, Les Lanes Sud et La Tuilerie à Foncouverte; Le Ruisseau de Torrent et Le Coucou à Camplong-d'Aude);

- et enfin, dans le Béarn, dans le département des Pyrénées-Atlantiques, au sud de Pau (La Tuilerie à Gan).

\section{ABRÉVIATIONS}

CINZ Code international de nomenclature zoologique (1999);

MNHN Muséum national d'Histoire naturelle, collection de Paléontologie, Paris;

BMNH Palaeontology Department of the Natural History Museum, Londres.

\section{SYSTÉMATIQUE}

Il existe dans les proportions des rhyncholites une variation intra-spécifique considérable et un degré important de rapprochement dans la morphologie des rhyncholites appartenant à différentes espèces (Müller 1963; Saunders et al. 1978) (Fig. 3). Les spécimens du Paléogène sont encore relativement peu nombreux et il n'existe aucune donnée relative à la variabilité des rhyncholites des espèces actuelles de Nautiles. Peu de renseignements sont disponibles sur le développement ontogénétique des rhyncholites actuels et fossiles. Malgré tout, certains caractères tels que l'importance relative de la hampe par rapport au capuchon (que traduisent les rapports $\mathrm{lh} / \mathrm{lc}$ et $\mathrm{lh} / \mathrm{l}$ ), leur faible variabilité au sein des espèces, la forme générale du rhyncholite (Fig. 12), l'aspect du capuchon (que traduit le rapport $1 / \mathrm{L}$ ), la convexité des bords latéro-antérieurs et la morphologie de la face ventrale permettent une distinction des différentes espèces. Nous sommes de l'avis de Saunders et al. (1978) quant à l'utilisation d'une para-taxonomie pour classer ces éléments isolés de la mandibule des Nautiles; elle nous a paru nécessaire. Nous ne pouvons attribuer de façon fiable ces rhyncholites à aucun genre précis de Nautiles.

Nous avons comparé les rhyncholites du Paléogène des Bassins de Paris et d'Aquitaine et des Corbières avec des espèces similaires du genre Rhyncolites. Une comparaison des dimensions est présentée dans le Tableau 2. Nous profitons également de ce travail et présentons en annexe de cette étude la description de Rhyncolites erroitegiensis $\mathrm{n}$. sp. du Thanétien d'Espagne et de Rhyncolites dutemplei (d'Orbigny, 1847) du Campanien de la Marne dont nous venons de retrouver le matériel type égaré dès 1847. 

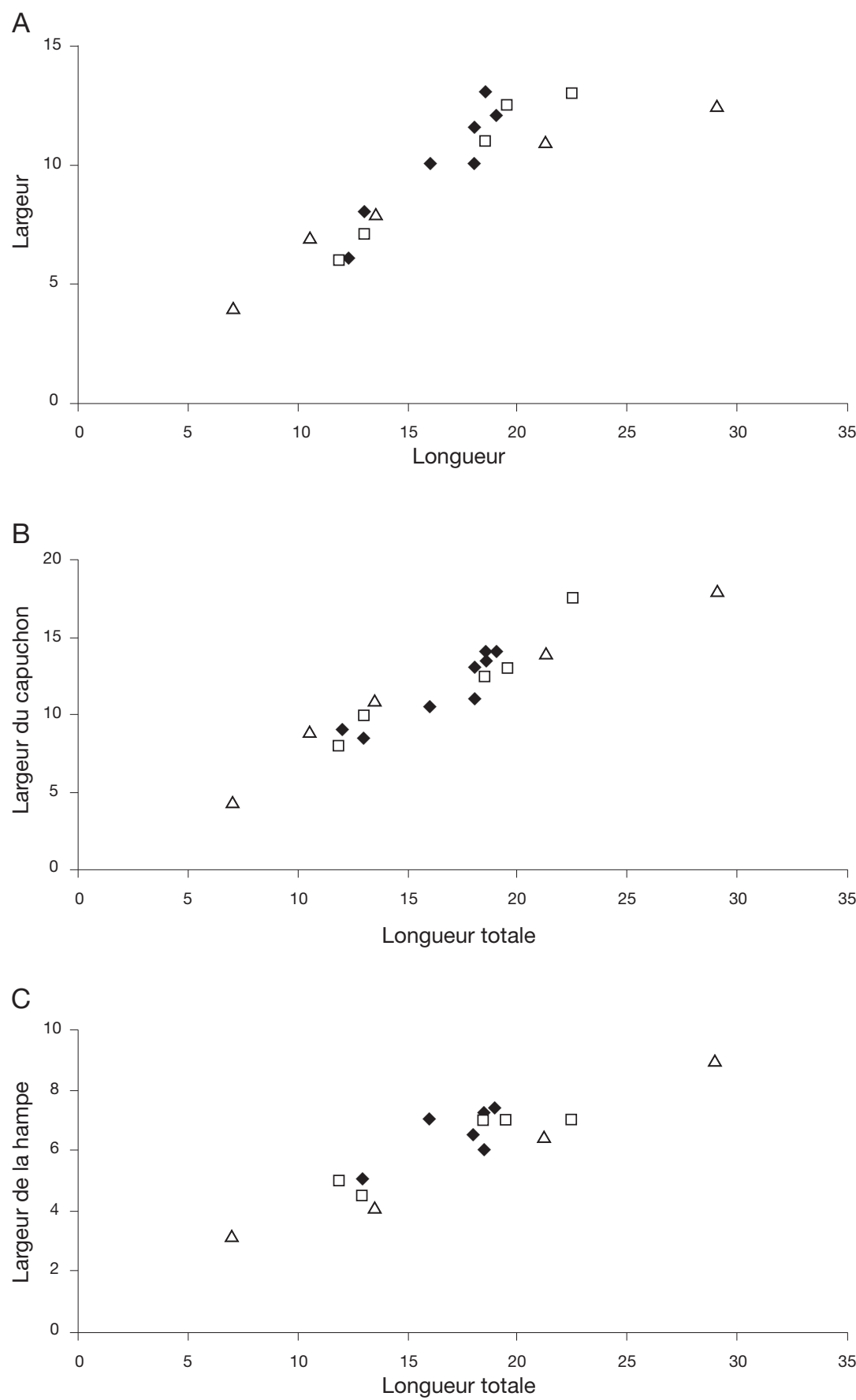

FIG. 3. - Analyses biométriques (dimensions en $\mathrm{mm}$ ) des rapports: A, entre longueur totale et largeur totale; $\mathbf{B}$, entre longueur totale et longueur du capuchon; C, entre longueur totale et largeur de la hampe chez Rhyncolites vilcassinus n. sp. $(\bullet), R$. sagittarius n. sp. ( $\square)$ et $R$. corbaricus n. sp. $(\Delta)$. 
Tableau 3. - Dimensions de Rhyncolites vilcassinus n. sp. Abréviations: voir Figure 2.

\begin{tabular}{lcccccccccccccc}
\hline & $\begin{array}{c}\mathbf{L} \\
(\mathrm{mm})\end{array}$ & $\begin{array}{c}\text { I } \\
(\mathrm{mm})\end{array}$ & $\begin{array}{c}\mathbf{H} \\
(\mathrm{mm})\end{array}$ & $\begin{array}{c}\text { Lc } \\
(\mathrm{mm})\end{array}$ & $\begin{array}{c}\text { Lh } \\
(\mathrm{mm})\end{array}$ & $\begin{array}{c}\text { Ih } \\
(\mathrm{mm})\end{array}$ & $\mathbf{l} / \mathbf{L}$ & $\mathbf{H} / \mathbf{L}$ & $\mathbf{l h} / \mathbf{l}$ & $\mathbf{L h} / \mathbf{L c}$ & $\boldsymbol{\alpha}$ & $\beta$ & $\gamma$ & $\delta$ \\
\hline Holotype & 18,5 & 11 & 9 & 14 & 10 & 6 & 0,60 & 0,49 & 0,55 & 0,71 & $75^{\circ}$ & $100^{\circ}$ & $60^{\circ}$ & $113^{\circ}$ \\
Paratype 1 & 16 & 10 & 9 & 10,5 & 10,5 & 7 & 0,60 & 0,56 & 0,70 & 1 & $80^{\circ}$ & $160^{\circ}$ & $68^{\circ}$ & $109^{\circ}$ \\
Paratype 2 & 18,5 & 13 & 9 & 13,5 & 9,6 & 7,2 & 0,70 & 0,49 & 0,55 & 0,71 & $72^{\circ}$ & $135^{\circ}$ & $43^{\circ}$ & $128^{\circ}$ \\
Paratype 3 & 18 & 11,5 & 9 & 13 & 9,8 & 6,5 & 0,63 & 0,50 & 0,56 & 0,75 & $82^{\circ}$ & $118^{\circ}$ & $60^{\circ}$ & $110^{\circ}$ \\
Paratype 4 & 12 & 6 & 5 & 9 & 7 & 5 & 0,50 & 0,42 & 0,83 & 0,77 & $67^{\circ}$ & $100^{\circ}$ & $40^{\circ}$ & $113^{\circ}$ \\
Paratype 5 & - & - & 5,5 & 9 & - & - & - & - & - & - & - & - & - & - \\
Paratype 6 & 13 & 8 & 6,5 & 8,5 & 7,5 & 5 & 0,61 & 0,50 & 0,62 & 0,88 & $78^{\circ}$ & $115^{\circ}$ & $36^{\circ}$ & $117^{\circ}$ \\
Paratype 7 & - & 10,5 & 7 & 10 & - & - & - & - & - & - & $74^{\circ}$ & $140^{\circ}$ & $54^{\circ}$ & - \\
Paratype 8 & 18 & 10 & 7 & 11 & 11 & 6,5 & 0,55 & 0,38 & 0,65 & 1 & $70^{\circ}$ & $120^{\circ}$ & $41^{\circ}$ & $113^{\circ}$ \\
Paratype 9 & - & - & 3 & 6 & - & - & - & - & - & - & - & - & - & - \\
Paratype 10 & 19 & 12 & 10 & 14 & 11 & 7,4 & 0,63 & 0,52 & 0,61 & 0,78 & $84^{\circ}$ & $94^{\circ}$ & $46^{\circ}$ & $100^{\circ}$ \\
\hline
\end{tabular}

Classe CEPHALOPODA Cuvier, 1798

Sous-classe NAUTILOIDA Agassiz, 1847

Ordre NAUTILOIDEA Agassiz, 1847

Famille incertae sedis

Genre Rhyncolites Biguet, 1819

ESPĖCE TYPE. - Rhyncolites hirundo Biguet, 1819 (par désignation subséquente, Teichert et al. 1964).

\section{Rhyncolites vilcassinus $\mathrm{n}$. sp.}

(Figs $4 ; 5 ; 12$ )

MATÉRIEL TYPE. - Holotype (MNHN A16777, coll. Faullummel). Paratypes, 5 exemplaires provenant du Bois du But, Fontenay-en-Vexin (Eure) : spécimen no 1 (MNHN A12390, coll. Schtrock); spécimens no 2 et no 3 (MNHN A27214 et MNHN A27215, leg. Pacaud); spécimen no 4 (MNHN A27270, leg. Marcomini); spécimen $\mathrm{n}^{\circ} 10$ (MNHN A27282, leg. Boucher). 1 exemplaire provenant de Fercourt (Oise): spécimen no 5 (MNHN A13622, leg. Pacaud). 1 exemplaire provenant des Garennes, Chaussy (Val d'Oise): spécimen nº 6 (MNHN A27216, leg. Ledon). 2 exemplaires provenant de Champagne-sur-Oise (Val d'Oise): spécimens no 7 et no 8 (MNHN A27217 et MNHN A27218, leg. Lhomme). 1 exemplaire provenant de Breuil (Eure): spécimen no 9 (MNHN A27219, leg. Dutheil).

Étymologie. - Du Pagus Vilcassinus (le Vexin) sa région type.

Localité type. - Bois du But, Fontenay-en-Vexin (Eure).

ÉTAGE TYPE. — Lutétien (Éocène moyen).

Dimensions. - Voir Tableau 3.

\section{DESCRIPTION}

Le capuchon est bien développé, de forme sub-rhomboédrique et à l'apex bien marqué et pointu. La hampe est haute et longue. Étroite dans sa partie médiane, elle est élargie dans sa partie postérieure. La face dorsale du capuchon est partagée en deux parties égales par une crête médiane antérieure largement arrondie. Sa surface est marquée de stries, nombreuses et parallèles, induites par plusieurs couches concentriques. Les bords latéro-antérieur et latéro-postérieur sont tranchants et concaves. Les bords latéro-antérieurs présentent un contour concave très important, accentuant l'apex. Lextrémité postérieure des bords latéro-antérieurs est fortement pointue, dépassant largement la face ventrale (caractère visible sur le paratype no 7). La crête médiane postérieure de la hampe est légèrement convexe et peu marquée, fuyante. Les crêtes latérales postérieures présentent une angulosité à peine soulignée sur la hampe. Les flancs de la hampe, dans la zone des points latéro-antérieurs internes, sont légèrement concaves. La face ventrale est marquée par une arête médiane saillante, de section arrondie, assez élevée au niveau de l'apex, elle présente, au-delà des parties latérales concaves du capuchon, une légère convexité. Elle s'atténue juste avant d'atteindre l'extrémité postérieure. Les bords de la hampe sont surélevés et tranchants. De chaque côté de l'arête médiane on distingue sur la face ventrale de la hampe des sillons s'étendant jusqu'au point postérieur. Ces sillons, dans la zone des parties latérales concaves, se prolongent jusque sur les bords latéro-antérieurs où ils découpent en de légers crans les bords tranchants et concaves 


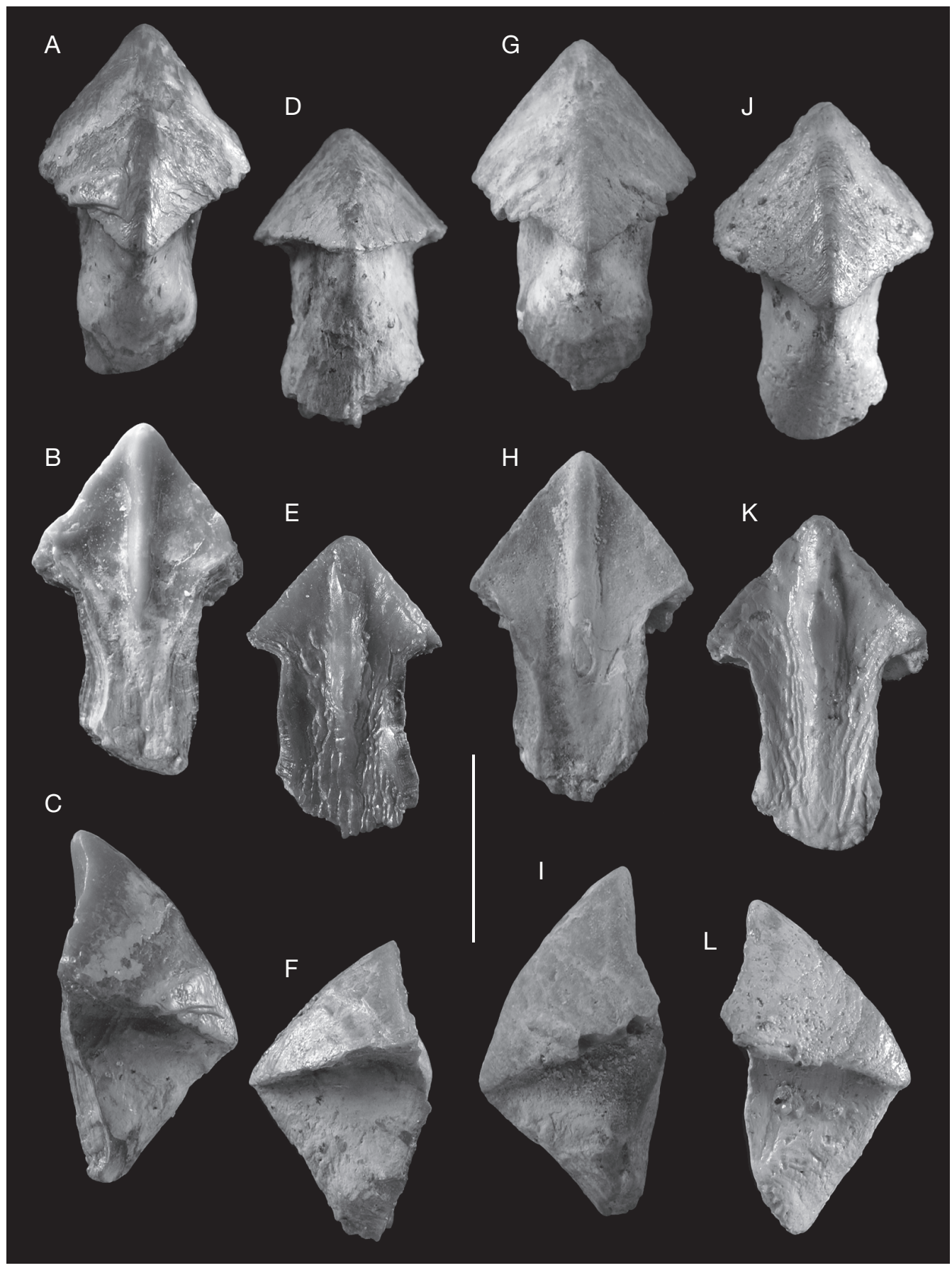

FIG. 4. - Rhyncolites vilcassinus n. sp., Bois du But, Fontenay-en-Vexin, Eure; A-C, holotype, MNHN A16777 (coll. Faullummel); D-F, paratype $n^{\circ}$ 1, MNHN A12390 (coll. Schtrock); G-I, paratype $n^{\circ}$ 10, MNHN A27282 (leg. Boucher); J-L, paratype $n^{\circ} 3$, MNHN $^{2}$ A27215 (leg. Pacaud). Échelle: $10 \mathrm{~mm}$. 
(caractère visible sur le paratype $\mathrm{n}^{\circ} 7$ ). Dans la zone des points latéro-antérieurs internes, sous les bords latéro-postérieurs, la hampe du paratype no 8 montre des traces de matière organique sombre et correspondant à l'insertion des feuilles conchiolinitiques de la mandibule supérieure.

\section{REMARQUES}

Le paratype no 7 (Fig. 5C-E) provenant du Lutétien inférieur de Champagne-sur-Oise (Val d'Oise) montre un exemplaire, quoique brisé à la base $\mathrm{du}$ capuchon (absence de hampe), d'une rare fraîcheur sur lequel la calcite s'est moins accumulée. De fait, il présente des caractères qui, chez les autres spécimens, sont plus ou moins atténués ou altérés. Les contours des bords latéro-antérieurs du capuchon sont en effet très concaves, l'apex est pointu, l'extrémité postérieure des bords latéro-antérieurs se termine en pointes aiguës, dépassant nettement la face ventrale (rappelant celles observées chez Rhyncolites dutemplei du Campanien décrit ci-après) et les sillons observés sur la face ventrale découpent les bords latéro-antérieurs tranchants en de légers crans. Ces sillons, servant semble t-il à améliorer la prise de la nourriture, n’ont été observés que chez cette espèce.

Le rhyncholite le plus similaire à Rhyncolites vilcassinus $\mathrm{n}$. sp. est $R$. corbaricus $\mathrm{n}$. sp. de l'Ilerdien des Corbières décrit ci-après. L'espèce du Bassin de Paris en differe cependant par une arête médiane présentant une partie convexe beaucoup moins saillante, plus élevée au niveau de l'apex et se prolongeant plus loin en s'atténuant près de l'extrémité postérieure de la hampe. Rhyncolites corbaricus $\mathrm{n}$. sp. présente de plus une hampe aux flancs fortement concaves et surélevés correspondant à l'insertion de la paroi conchyolinitique de la mandibule supérieure. Rhyncolites shinfieldensis de l'Yprésien d'Angleterre et des corbières présente une taille plus réduite et montre sur sa face ventrale une arête médiane disparaissant insensiblement après la protubérance servant à écraser les proies, alors qu'elle se prolonge chez $R$. vilcassinus n. sp. jusqu'à l'extrémité du point postérieur de la hampe, sans protubérance, mais seulement avec une partie de l'arête médiane convexe. Le rhyncholite du Bassin de Paris présente également une crête médiane postérieure plus convexe que celle visible chez $R$. shinfieldensis. Les rhyncholites du Lutétien belge (Vincent 1901: vii, viii ; Glibert 1933: 189, 190) diffèrent de $R$. vilcassinus n. sp. par une crête médiane postérieure de la hampe au contour nettement concave, par leur arête médiane ventrale disparaissant après une protubérance pour l'un (spécimens des figures 15-17 de Vincent 1901) et après la zone des points latéro-antérieurs internes pour les autres (spécimens des figures 9-14 de Vincent 1901). De plus, chez ces derniers, l'arête médiane ne présente aucune convexité. Le rhyncholite figuré par Deshayes (1835: pl. 99, figs 3-5) dont nous ne retrouvons aucune mention dans le texte de cet auteur, se rapproche de ces derniers exemplaires et provient en fait de Belgique et non du Bassin de Paris (comparer les figures 4 de Deshayes 1835 et 14 de Vincent 1901) conformément au texte de Nyst (1845: 616, pl. 46, fig. 3) qui écrit: «Nous avons recueilli dans les sables de Laecken, un corps qui a été rapporté par M. Deshayes à la mandibule supérieure d'un Nautile, et dont il a donné une bonne figure [...]». Ce spécimen est rapporté dubitativement par Cossmann (1892: 10) à Eutrephoceras umbilicare (Deshayes, 1835) sans même connaître l'origine de l'exemplaire. C'est donc par erreur que de nombreux auteurs citent la figure de Deshayes pour signaler la présence de rhyncholites dans l'Éocène du Bassin de Paris.

\section{Rhyncolites sagittarius $\mathrm{n} . \mathrm{sp}$.}

(Figs $6 ; 12$ )

MatéRIEl TYPE. - Holotype (MNHN A27220, leg. Pacaud). Paratypes, 2 exemplaires provenant de Chaumont-en-Vexin (Oise) : spécimen no 1 (MNHN A27221, leg. Pacaud), spécimen no 2 (coll. Dordonat, copie MNHN A27279). 1 exemplaire provenant de Cauvigny (Oise), spécimen no 3 (MNHN A27222, leg. Pattedoie). 1 exemplaire provenant de Breuil (Eure), spécimen no 4 (MNHN A27222, leg. Dutheil).

ÉTYMOLOGIE. - Du latin sagittarius, l'archer. Allusion à la forme en flèche du genre Rhyncolites.

Localité type. - Chaumont-en-Vexin (Oise).

ÉTAGE TYPE. — Lutétien (Éocène moyen).

Dimensions. - Voir Tableau 4. 


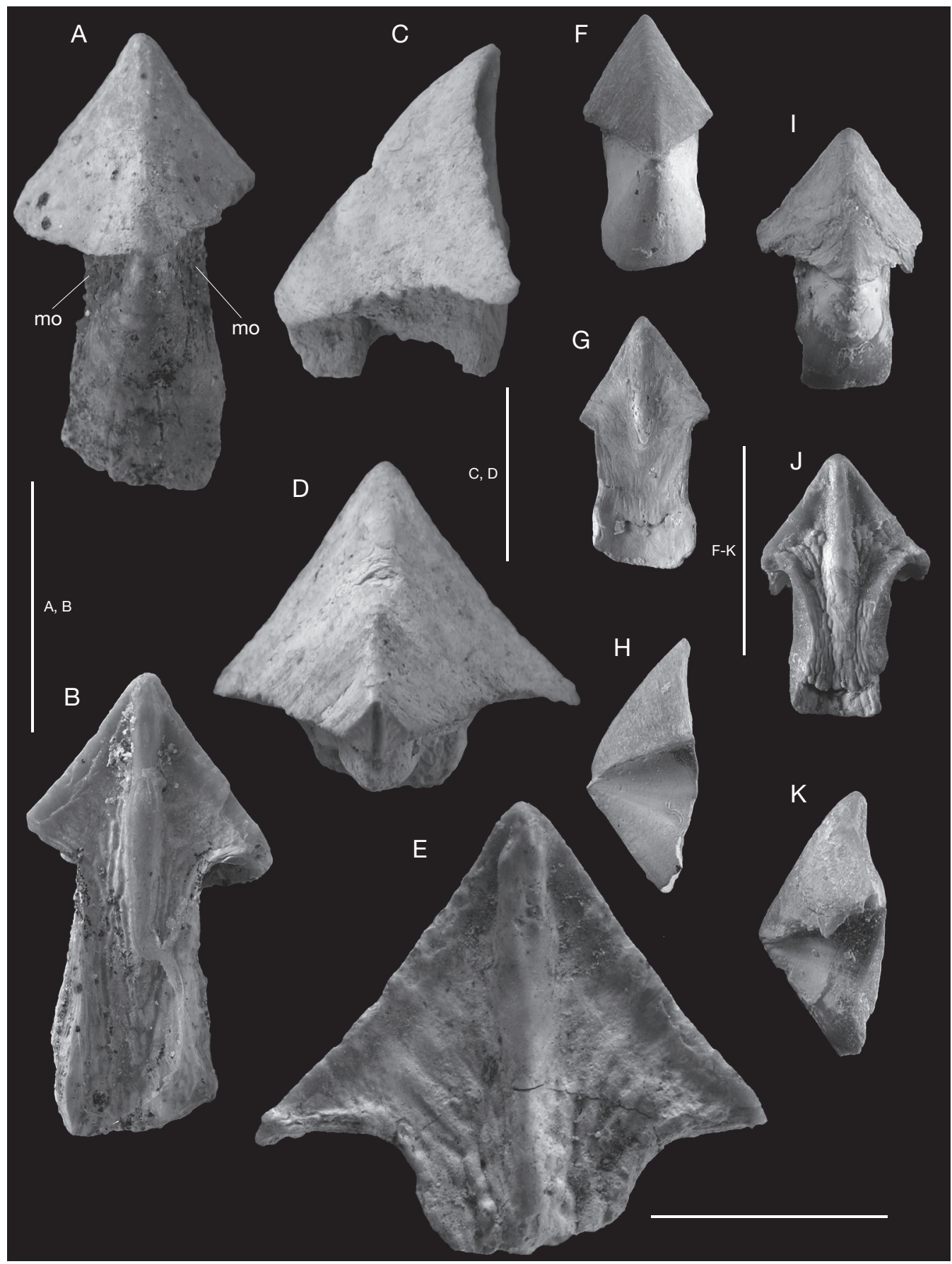

FIG. 5. - Rhyncolites vilcassinus n. sp.: A, B, paratype $n^{\circ} 8$, MNHN A27218 (leg. Lhomme), Champagne-sur-Oise, Val d'Oise; C-E, paratype $n^{\circ} 7$, MNHN A27217 (leg. Lhomme), Champagne-sur-Oise, Val d'Oise; F-H, paratype n 4, MNHN A27270 (leg. Marcomini), Bois du But, Fontenay-en-Vexin, Eure; I-K, paratype n 6, MNHN A27216 (leg. Ledon), Les Garennes, Chaussy, Val d'Oise. Abréviation: mo, traces de matière organique. Échelles: A, B, F-K, 10 mm; C-E, 5 mm. 
TABLEAU 4. - Dimensions de Rhyncolites sagittarius n. sp. Abréviations: voir Figure 2.

\begin{tabular}{lcccccccccccccc}
\hline & $\begin{array}{c}\mathbf{L} \\
(\mathrm{mm})\end{array}$ & $\begin{array}{c}\text { I } \\
(\mathrm{mm})\end{array}$ & $\begin{array}{c}\mathbf{H} \\
(\mathrm{mm})\end{array}$ & $\begin{array}{c}\text { Lc } \\
(\mathrm{mm})\end{array}$ & $\begin{array}{c}\text { Lh } \\
(\mathrm{mm})\end{array}$ & $\begin{array}{c}\text { Ih } \\
(\mathrm{mm})\end{array}$ & $\mathbf{l} / \mathbf{L}$ & $\mathbf{H} / \mathbf{L}$ & $\mathbf{I h} / \mathbf{I}$ & $\mathbf{L h} / \mathbf{L c}$ & $\boldsymbol{\alpha}$ & $\beta$ & $\boldsymbol{\gamma}$ & $\delta$ \\
\hline Holotype & 18,5 & 11 & 8,1 & 12,5 & 9 & 7 & 0,60 & 0,44 & 0,63 & 0,72 & $78^{\circ}$ & $91^{\circ}$ & $48^{\circ}$ & $120^{\circ}$ \\
Paratype 1 & 22,5 & 13 & 11 & 17,5 & 11 & 7 & 0,58 & 0,49 & 0,84 & 0,62 & $68^{\circ}$ & $117^{\circ}$ & $42^{\circ}$ & $93^{\circ}$ \\
Paratype 2 & 19,5 & 12,5 & 8 & 13 & 9 & 7 & 0,64 & 0,41 & 0,56 & 0,69 & $82^{\circ}$ & $90^{\circ}$ & $53^{\circ}$ & $132^{\circ}$ \\
Paratype 3 & 11,9 & 6 & 4,1 & 8 & 5,8 & 5 & 0,50 & 0,34 & 0,83 & 0,72 & $85^{\circ}$ & $85^{\circ}$ & $33^{\circ}$ & $122^{\circ}$ \\
Paratype 4 & 13 & 7,1 & 6 & 10 & 6,1 & 4,5 & 0,55 & 0,47 & 0,63 & 0,61 & $75^{\circ}$ & $93^{\circ}$ & $55^{\circ}$ & $117^{\circ}$ \\
\hline
\end{tabular}

\section{DESCRIPTION}

Le capuchon est particulièrement développé en longueur, de forme sub-rhomboédrique et présente un apex très pointu. La hampe est très haute et courte. Étroite dans sa partie médiane, elle est élargie dans sa partie postérieure. La face dorsale du capuchon est partagée en deux parties égales par une crête médiane antérieure bien marquée. Sa surface est marquée de nombreuses stries parallèles. Les bords latéro-antérieur et latéro-postérieur sont tranchants. Le bord latéro-antérieur présente un profil légèrement sigmoïdal, convexe dans sa plus grande longueur, puis subitement concave près de l'apex en accentuant la pointe. La crête médiane postérieure de la hampe est fuyante, fortement convexe à cause de la présence d'une forte callosité au niveau du vertex. Les crêtes latérales postérieures présentent une angulosité soulignée. Les flancs de la hampe dans la zone des points latéro-antérieurs internes sont légèrement concaves. La face ventrale est marquée par une arête médiane saillante, de section arrondie, assez élevée au niveau de l'apex, elle s'abaisse ensuite, puis présente, au-delà des parties latérales concaves du capuchon, une légère convexité et un élargissement formant ainsi une protubérance. Elle s'atténue avant d'atteindre l'extrémité postérieure. Les bords de la hampe sont surélevés et tranchants. La surface ventrale de la hampe est lisse de chaque côté de l'arête médiane.

\section{REMARQUES}

Le paratype no 4 (Fig. 6L) est de taille beaucoup plus réduite, sa longueur totale ne dépassant pas $13 \mathrm{~mm}$ (holotype: 18,5 mm, paratype no 1 : $22,5 \mathrm{~mm}$ ). Il présente une hampe sans callosité au niveau du vertex, mais les autres caractères prin- cipaux, proportions du capuchon et la courbure légèrement sigmoïdale des bords latéro-antérieurs, sont semblables. Nous considérons ce spécimen comme une variation individuelle ou ontogénétique. Rhyncolites sagittarius $\mathrm{n}$. $\mathrm{sp}$. diffère de $R$. vilcassinus $\mathrm{n}$. sp. par son capuchon présentant des bords latéro-antérieurs concaves, au profil sigmoïdal, par son apex plus aigu, par la callosité de la hampe à la base du vertex, par la protubérance de l'arête médiane de la face ventrale et par l'absence de sillons de chaque côté de cette arête et sur les parties latérales concaves. Rhyncolites shinfieldensis, autre rhyncholite présentant une protubérance de l'arête médiane ventrale, en diffère par l'absence de callosité de la hampe, par la protubérance de l'arête médiane ventrale située plus au centre sous le capuchon. Rhyncolites aethioparion de l'Yprésien d'Angleterre et des Corbières présente une hampe beaucoup plus large et un capuchon plus court. Les deux rhyncholites anglais montrent également une arête médiane disparaissant avant d'atteindre le point postérieur de la hampe. Le rhyncholite du Lutétien belge montrant une protubérance de l'arête médiane ventrale (Vincent 1901: figs 15-17) en diffère par ses bords latéro-antérieurs au profil concave et par l'arête médiane disparaissant également avant d'atteindre le point postérieur. Rhyncolites oppenheimi Till, 1911 (pro Rhyncolites sp. Oppenheim 1906) de l'Éocène d'Égypte (Afrique) présente comme chez notre rhyncholite une arête médiane ventrale qui s'étend jusqu'à l'extrémité du point postérieur et une protubérance située au même endroit. Il diffère toutefois de $R$. sagittarius n. sp. par des dimensions plus importantes ( 44 $\mathrm{mm}$ ), par une hampe beaucoup plus longue, par un capuchon plus court en arrière et un contour des bords latéro-antérieurs nettement concave. 


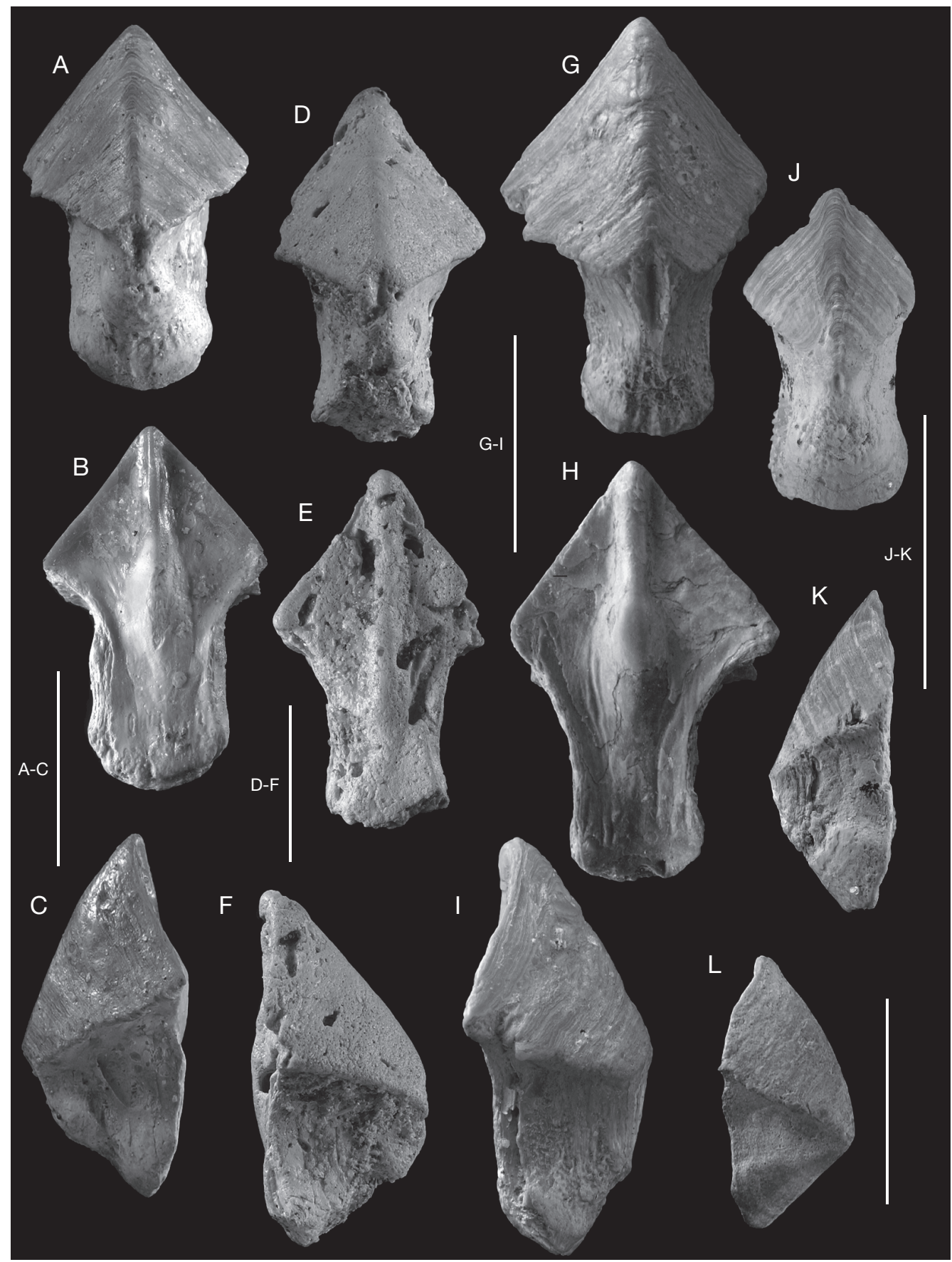

FIG. 6. - Rhyncolites sagittarius n. sp.: A-C, holotype, MNHN A27220 (leg. Pacaud), Chaumont-en-Vexin, Oise; D-F, paratype $\mathrm{n}^{\circ} 1$, MNHN A27221 (leg. Pacaud), Chaumont-en-Vexin, Oise; G-I, paratype $\mathrm{n}^{\circ} 2$ (coll. Dordonat, copie MNHN A27279), Chaumont-enVexin, Oise; J, K, paratype ${ }^{\circ}$ 3, MNHN A27438 (leg. Pattedoie), Cauvigny (Oise); L, paratype $n^{\circ}$ 4, MNHN A27222 (leg. Dutheil), Breuil (Eure). Échelles: $10 \mathrm{~mm}$. 
TABlEAU 5. - Dimensions de Rhyncolites Ihommei n. sp. Abréviations: voir Figure 2.

\begin{tabular}{lcccccccccccccc}
\hline & $\mathbf{L}$ & $\mathbf{I}$ & $\mathbf{H}$ & $\mathbf{L c}$ & $\mathbf{L h}$ & $\mathbf{l h}$ & & & & & & \\
& $(\mathrm{mm})$ & $(\mathrm{mm})$ & $(\mathrm{mm})$ & $(\mathrm{mm})$ & $(\mathrm{mm})$ & $(\mathrm{mm})$ & $\mathbf{I} \mathbf{L}$ & $\mathbf{H} / \mathbf{L}$ & $\mathbf{l h} / \mathbf{I}$ & $\mathbf{L h} / \mathbf{L c}$ & $\boldsymbol{\alpha}$ & $\beta$ & $\gamma$ & $\delta$ \\
\hline Holotype & 7,9 & 5,2 & 2,8 & 4 & 3,9 & 3,5 & 0,65 & 0,35 & 0,67 & 0,97 & $85^{\circ}$ & $130^{\circ}$ & $50^{\circ}$ & $114^{\circ}$ \\
Paratype & 6,3 & 4 & 1,5 & 2,5 & 3,5 & 2,8 & 0,63 & 0,23 & 0,70 & 1,40 & $83^{\circ}$ & $90^{\circ}$ & $50^{\circ}$ & $125^{\circ}$ \\
\hline
\end{tabular}

Rhyncolites lhommei n. sp.

(Figs 11A-F; 12)

MATÉRIel TYPe. - Holotype (MNHN A27223, leg. Lhomme). Paratype, (MNHN A27224, leg. Lhomme).

ÉTYMOLOGIE. - Dédié à Jean-François Lhomme qui a récolté le matériel.

LOCAlité TYPE. - Champagne-sur-Oise (Val d'Oise).

ÉTAGE TYPE. — Lutétien inférieur (Éocène inférieur).

Dimensions. - Voir Tableau 5.

\section{DESCRIPTION}

Rhyncholite de taille relativement réduite. Le capuchon est peu développé, aplati, de forme triangulaire et à l'apex pointu. La hampe est courte et basse. Large après le capuchon, elle est étroite dans sa partie postérieure. La face dorsale du capuchon est partagée en deux parties égales par une crête médiane antérieure largement arrondie. Sa surface est marquée de stries, nombreuses et parallèles, induites par plusieurs couches concentriques. Les bords latéro-antérieur et latéro-postérieur sont tranchants et faiblement concaves, presque droits. La zone médiane postérieure de la hampe présente une dépression qui, partant du vertex, se prolonge sur la hampe, sans atteindre pour autant l'extrémité du point postérieur. Les crêtes latérales postérieures présentent une angulosité à peine soulignée. Les flancs de la hampe sont légèrement concaves. La face ventrale est marquée par une arête médiane saillante qui présente une légère convexité dans la zone des parties latérales concaves du capuchon. Elle s'atténue très vite, bien avant d'atteindre l'extrémité postérieure. De chaque côté de l'arête médiane on distingue sur la face ventrale de la hampe des sillons fins s'étendant jusqu'au point postérieur.
REMARQUES

Rhyncolites lhommei n. sp. diffère des autres rhyncholites par sa petite taille, par la forme de son capuchon, triangulaire et aplati, par la présence d'une dépression en lieu et place d'une crête médiane postérieure de la hampe. La convexité de l'arête médiane servant à écraser les proies est située dans la zone des parties latérales concaves du capuchon alors qu'elle est située au-delà chez $R$. vilcassinus n. sp. Rhyncolites shinfieldensis, autre rhyncholite de petite dimension ( $\mathrm{L}$ maxi: $7 \mathrm{~mm}$ ), présente un capuchon de forme rhomboédrique à l'angle $\beta$ plus fermé $\left(80^{\circ}\right.$ chez l'holotype pour $130^{\circ} \mathrm{chez}$ $R$. lhommei n. sp.). L'arête médiane de la face ventrale présente de plus une protubérance absente chez $R$. lhommei n. sp. Rhyncolites sp. Teichert \& Stanley 1975 de l'Éocène d'Ardath Shale (Californie) est morphologiquement similaire aux espèces éocènes décrites d'Angleterre et diffère donc de R. lhommei n. sp.

\section{Rhyncolites shinfieldensis \\ Ward \& Cooper, 1972 \\ (Figs 8A-C; 12)}

Rhyncolites shinfieldensis Ward \& Cooper 1972: 407, 408, figs 2, 3. — Teichert \& Stanley 1975: 180.

MatéRIel Type. - Holotype (BMNH C77557). Paratype (BMNH C77558).

LOCALITÉ TYPe. - Shinfield (Angleterre).

ÉTAGE TYPE. - Yprésien (London Clay, Éocène inférieur).

Matériel eXAMiné. - Un exemplaire (coll. Martinez, copie MNHN A27370). Ilerdien (Yprésien, Éocène inférieur) de Requy, Montlaur (Aude).

Dimensions. - Voir Tableau 6. 


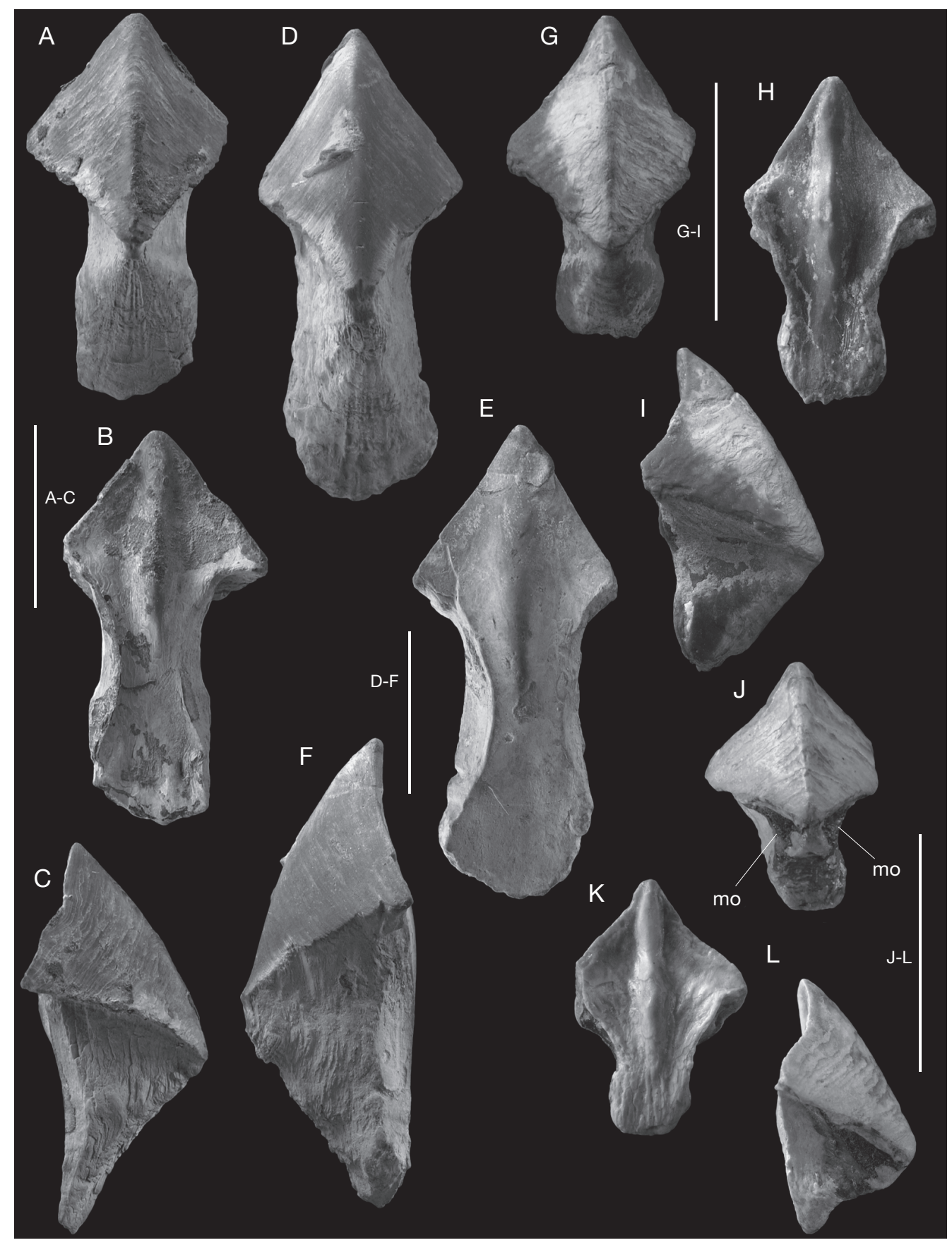

FIG. 7. - Rhyncolites corbaricus n. sp.: A-C, holotype (coll. Martinez, copie MNHN A27310), Lavade, Fontcouverte, Aude; D-F, paratype $n^{\circ} 1$ (coll. Martinez, copie MNHN A27311), La Tuilerie, Fontcouverte, Aude; G-I, paratype $n^{\circ} 2$ (coll. Martinez, copie MNHN A27312), Le Ruisseau de Torrent, Camplong-d'Aude, Aude; J-L, paratype nº 3 (coll. Martinez, copie MNHN A27313), Le Coucou, Camplong-d'Aude, Aude. Abréviation: mo, traces de matière organique. Échelles: $10 \mathrm{~mm}$. 
TABlEAU 6. - Dimensions de Rhyncolites shinfieldensis Ward \& Cooper, 1972. Abréviations: voir Figure 2.

\begin{tabular}{|c|c|c|c|c|c|c|c|c|c|c|c|c|c|c|}
\hline & $\underset{(\mathrm{mm})}{\mathbf{L}}$ & $\begin{array}{c}\text { I } \\
(\mathrm{mm})\end{array}$ & $\underset{(\mathrm{mm})}{\mathbf{H}}$ & $\begin{array}{c}\text { Lc } \\
(\mathrm{mm})\end{array}$ & $\begin{array}{c}\text { Lh } \\
(\mathrm{mm})\end{array}$ & $\begin{array}{l}\text { lh } \\
(\mathrm{mm})\end{array}$ & I/L & $\mathrm{H} / \mathrm{L}$ & Ih/I & Lh/Lc & $\alpha$ & $\beta$ & $\gamma$ & $\delta$ \\
\hline Coll. Martinez & 3 & 2 & 1,1 & 2,2 & 1,5 & 1 & 0,66 & 0,36 & 0,50 & 0,68 & $88^{\circ}$ & $94^{\circ}$ & $40^{\circ}$ & $125^{\circ}$ \\
\hline
\end{tabular}

TABLEAU 7. - Dimensions de Rhyncolites aethioparion Ward \& Cooper, 1972. Abréviations: voir Figure 2.

\begin{tabular}{cccccccccccccccc}
\hline & $\begin{array}{c}\mathbf{L} \\
(\mathrm{mm})\end{array}$ & $\begin{array}{c}\text { I } \\
(\mathrm{mm})\end{array}$ & $\begin{array}{c}\mathbf{H} \\
(\mathrm{mm})\end{array}$ & $\begin{array}{c}\text { Lc } \\
(\mathrm{mm})\end{array}$ & $\begin{array}{c}\text { Lh } \\
(\mathrm{mm})\end{array}$ & $\begin{array}{c}\text { Ih } \\
(\mathrm{mm})\end{array}$ & $\mathbf{I} / \mathbf{L}$ & $\mathbf{H} / \mathbf{L}$ & Ih/I & Lh/Lc & $\alpha$ & $\beta$ & $\boldsymbol{\gamma}$ & $\delta$ \\
\hline Coll. Martinez & 3 & 2 & 1,2 & 1,7 & 1,7 & 1,2 & 0,66 & 0,40 & 0,60 & 1 & $80^{\circ}$ & $115^{\circ}$ & $47^{\circ}$ & $128^{\circ}$ \\
\hline
\end{tabular}

\section{DESCRIPTION}

Le capuchon est bien développé, de forme sub-rhomboédrique et à l'apex bien marqué mais émoussé (usure). La hampe est très courte et basse. Large après le capuchon, elle est étroite dans sa partie postérieure. La face dorsale du capuchon est partagée en deux parties égales par une crête médiane antérieure largement arrondie. Sa surface est marquée de stries nombreuses et parallèles induites par plusieurs couches concentriques. Les bords latéroantérieur et latéro-postérieur sont tranchants et concaves. Les bords latéro-antérieurs présentent un contour concave peu prononcé. La crête médiane postérieure de la hampe est légèrement concave et peu marquée. Les crêtes latérales postérieures sont largement arrondies. Les flancs de la hampe sont légèrement concaves. La face ventrale est concave, marquée par une arête médiane peu saillante, assez élevée au niveau de l'apex, elle présente un épaississement au niveau des parties latérales concaves. Elle s'atténue à l'approche des points latéro-antérieurs internes.

\section{REMARQUES}

Le spécimen de Requy (Aude) correspond bien à $R$. shinfieldensis du London Clay de Shinfield (Angleterre), niveau contemporain de l'Ilerdien moyen. Le paratype, quoique d'une taille légèrement supérieure $(5,9 \mathrm{~mm})$, présente des caractères semblables à notre spécimen. L'holotype montre en revanche un capuchon moins long, une hauteur plus importante mais l'exemplaire des Corbières entre dans le cadre de cette espèce. Rhyncolites sp.
Teichert \& Stanley, 1975 de l'Éocène d'Ardath Shale (Californie), autre petite espèce, en diffère par une hampe plus large et par une arête médiane de la face ventrale sans protubérance.

\section{Rhyncolites aethioparion \\ Ward \& Cooper, 1972}

(Figs 8D-F; 12)

Rhyncolites aethioparion Ward \& Cooper 1972: 407, fig. 1a-c. — Teichert \& Stanley 1975: 180.

Rhyncolite [sic] aff. aethioparion - Martinez 1998: 7, pl. 2, fig. 3a-c.

MATÉRIEL TYPE. - Holotype (BMNH C77556).

LOCALITÉ TYPE. — Shinfield (Angleterre).

ÉTAGE TYPE. - Yprésien (London Clay, Éocène inférieur).

Matériel eXAminé. - Un exemplaire (coll. Martinez, copie MNHN A27371). Ilerdien (Yprésien, Éocène inférieur) de Montauriol, Servies-en-Val (Aude).

Dimensions. - Voir Tableau 7.

\section{DESCRIPTION}

Rhyncholite de taille relativement réduite. Le capuchon est bien développé, de forme sub-rhomboédrique et à l'apex bien marqué et pointu. La hampe est basse et longue. Étroite dans sa partie médiane, elle est élargie dans sa partie postérieure. La face dorsale du capuchon est partagée en deux parties égales par une crête médiane antérieure légèrement 


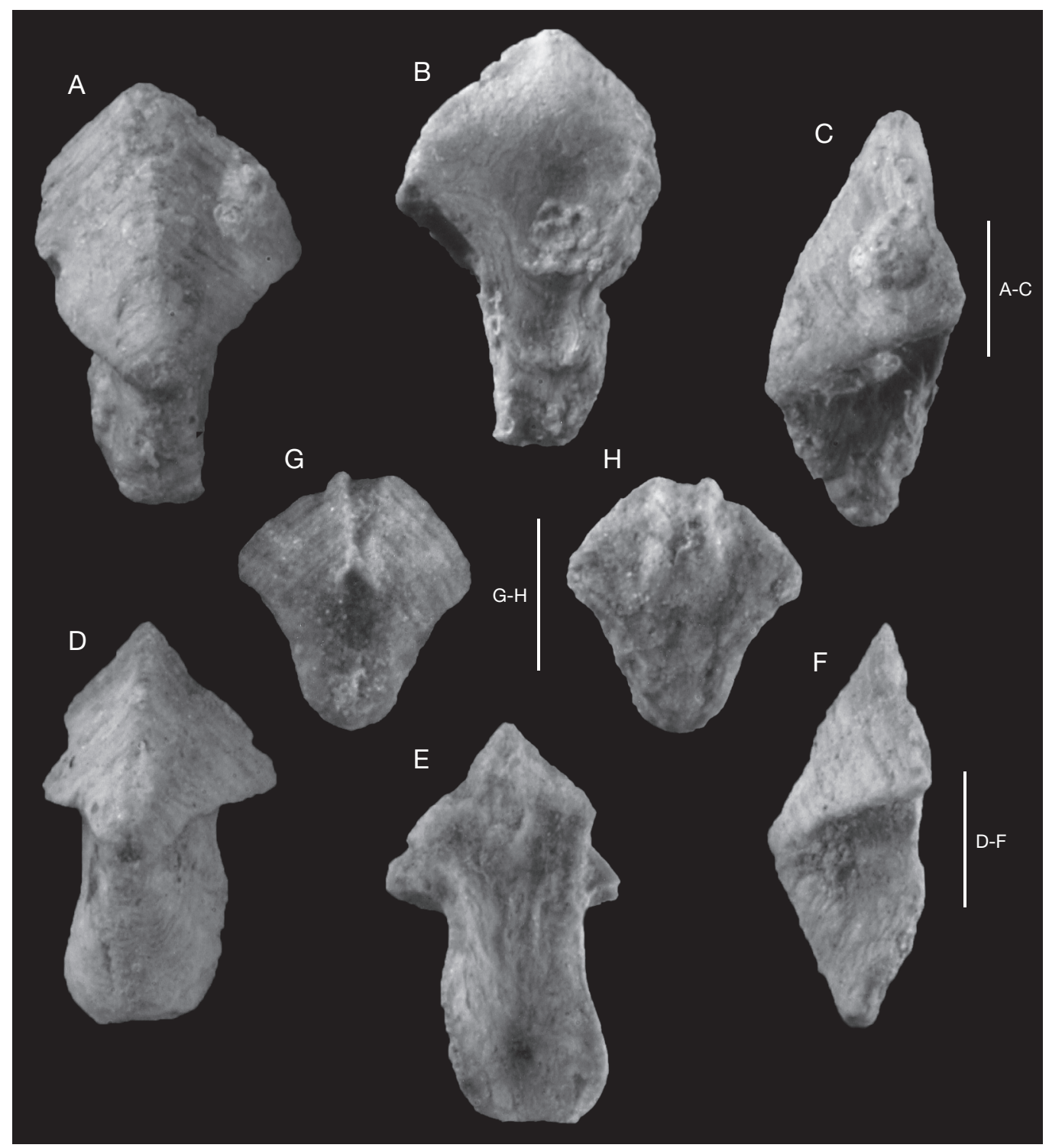

FIG. 8. - A-C, Rhyncolites shinfieldensis Ward \& Cooper, 1972, coll. Martinez (copie MNHN A27370), Requy, Montlaur, Aude; D-F, Rhyncolites aethioparion Ward \& Cooper, 1972, coll. Martinez (copie MNHN A27371), Servies-en-Val, Montauriol, Aude; G-H, Rhyncolites sp. (coll. Martinez), Le Coucou, Camplong-d'Aude, Aude. Échelles: A-C, 10 mm; D-H, 1 mm.

anguleuse. Sa surface est marquée de stries nombreuses et parallèles induites par plusieurs couches concentriques. Les bords latéro-antérieur et latéropostérieur sont tranchants et faiblement concaves. L'extrémité postérieure des bords latéro-antérieurs est fortement pointue, dépassant la face ventrale.
La crête médiane postérieure de la hampe est légèrement concave et peu marquée. Les crêtes latérales postérieures présentent une angulosité à peine soulignée. Les flancs de la hampe sont légèrement concaves. Dans la zone des points latéro-antérieurs, sous les bords latéro-postérieurs, la hampe montre 
TABleAu 8. - Dimensions de Rhyncolites corbaricus n. sp. Abréviations: voir Figure 2.

\begin{tabular}{|c|c|c|c|c|c|c|c|c|c|c|c|c|c|c|}
\hline & $\begin{array}{c}\mathbf{L} \\
(\mathrm{mm})\end{array}$ & $\begin{array}{c}\text { I } \\
(\mathrm{mm})\end{array}$ & $\begin{array}{c}\mathbf{H} \\
(\mathrm{mm})\end{array}$ & $\begin{array}{c}\text { Lc } \\
(\mathrm{mm})\end{array}$ & $\begin{array}{c}\text { Lh } \\
(\mathrm{mm})\end{array}$ & $\begin{array}{c}\mathbf{l h} \\
(\mathrm{mm})\end{array}$ & $\mathrm{I} / \mathrm{L}$ & H/L & Ih/I & Lh/Lc & $\alpha$ & $\beta$ & $\gamma$ & $\delta$ \\
\hline Holotype & 21,2 & 11 & 9,1 & 14 & 12 & 6,5 & 0,52 & 0,42 & 0,59 & 0,85 & $80^{\circ}$ & $88^{\circ}$ & $54^{\circ}$ & $108^{\circ}$ \\
\hline Paratype 1 & 29 & 12,5 & 10,5 & 18 & 15 & 9 & 0,43 & 0,36 & 0,72 & 0,83 & $64^{\circ}$ & $78^{\circ}$ & $40^{\circ}$ & $118^{\circ}$ \\
\hline Paratype 2 & 13,5 & 8 & 6,1 & 11 & 7 & 4,1 & 0,59 & 0,45 & 0,51 & 0,63 & $72^{\circ}$ & $92^{\circ}$ & $50^{\circ}$ & $120^{\circ}$ \\
\hline Paratype 3 & 10,5 & 7 & 5,5 & 9 & - & - & 0,66 & 0,52 & - & - & $81^{\circ}$ & $125^{\circ}$ & $53^{\circ}$ & - \\
\hline Paratype 4 & 7 & 4 & 3,5 & 4,5 & 4 & 3,2 & 0,57 & 0,50 & 0,80 & 0,88 & $83^{\circ}$ & $95^{\circ}$ & $50^{\circ}$ & $105^{\circ}$ \\
\hline
\end{tabular}

des traces de matière organique sombre et correspondant à l'insertion des feuilles conchiolinitiques de la mandibule supérieure. La face ventrale est marquée par une arête complètement effacée par une usure importante. Les bords de la hampe sont surélevés et la zone du point postérieur est fortement concave.

\section{REMARQUeS}

Comme le souligne Martinez (1998), l'unique spécimen récolté à Servies-en-Val (Aude) présente de grandes similitudes avec $R$. aethioparion du London Clay de Shinfield (Angleterre). La surface ventrale ne montre pas la protubérance de l'arête ventrale, ni même cette dernière, cette surface ayant subi une altération importante. On ne distingue, en lumière rasante, que la présence d'une arête ventrale sans plus de caractère. Toutefois, malgré des dimensions réduites, les seuls éléments observables, forme du rhyncholite, angles $\alpha$ et $\beta$ du capuchon semblables, hampe basse et longue, vont dans le sens d'un rapprochement avec l'espèce anglaise. Le spécimen de Servies-en-Val differre de Rhyncolites sp. Teichert \& Stanley, 1975 de l'Éocène d'Ardath Shale (Californie) par une hampe plus longue, aux flancs concaves dans la zone du point latéral antérieur interne.

\section{Rhyncolites corbaricus $\mathrm{n}$. $\mathrm{sp}$.}

(Figs $7 ; 12$ )

Nautilus sp. - Doncieux 1908: 27.

Rhyncolite [sic] sp. 1 - Martinez 1998: 5, 6, pl. 1, fig. 1a-c et pl. 3, figs 2, 3 .

Matériel tyPe. - Holotype (coll. Martinez, copie MNHN A27310). Paratypes, 4 exemplaires: spécimen no 1 (coll. Martinez, copie MNHN A27311), La Tuilerie, Foncouverte (Aude); spécimen no 2 (coll. Martinez, copie MNHN A27312), Le Ruisseau de Torrent, Camplongd'Aude (Aude); spécimen no 3 (coll. Martinez, copie MNHN A27313) et spécimen no 4 (MNHN A27255, leg. Vizcaino), Le Coucou, Camplong-d'Aude (Aude).

ÉTYMOLOGIE. - Des Corbières, sa région type.

LOCALITÉ TYPE. - Lavade, Fontcouverte (Aude).

ÉTAGE TYPE. - Ilerdien (Yprésien, Éocène inférieur).

Dimensions. - Voir Tableau 8.

\section{DESCRIPTION}

Le capuchon est bien développé, haut, de forme sub-rhomboédrique et à l'apex bien marqué et pointu. La hampe est fortement déclive, aplatie et longue. Étroite dans sa partie médiane, elle est élargie dans sa partie postérieure. La face dorsale du capuchon est partagée en deux parties égales par une crête médiane antérieure largement arrondie. Sa surface est marquée de stries, nombreuses et parallèles, induites par plusieurs couches concentriques. Les bords latéro-antérieur et latéro-postérieur sont tranchants et concaves. Les bords latéro-antérieurs présentent un contour concave très importants, accentuant l'apex. L'extrémité postérieure des bords latéro-antérieurs est pointue, dépassant largement la face ventrale (caractère visible sur l'holotype). La crête médiane postérieure de la hampe est peu marquée. Les crêtes latérales postérieures présentent une angulosité à peine soulignée sur la hampe. La hampe est marquée de nombreux sillons longitudinaux qui, partant du vertex, se prolongent jusqu'au point postérieur. Les flancs de la hampe, dans la zone des points latéro-antérieurs internes, sont légèrement concaves. La face ventrale est marquée par une arête médiane saillante, de section arrondie, peu élevée 


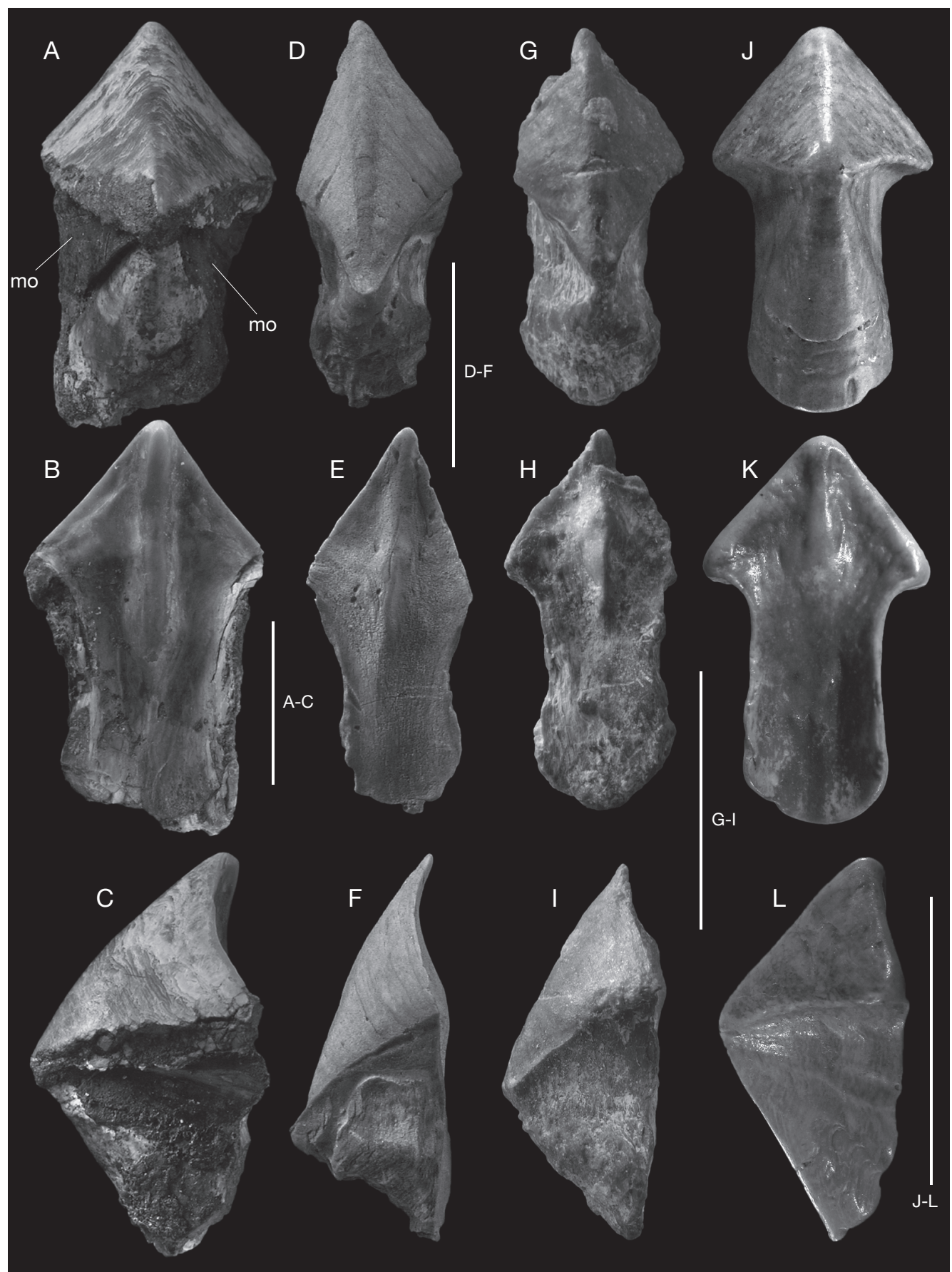

FIG. 9. - A-C, Rhyncolites guanensis n. sp., holotype, MNHN A27253 (leg. Belliard), La Tuilerie, Gan, Pyrénées-Atlantiques; D-F, Rhyncolites foncouvertensis n. sp., holotype, MNHN A27254 (leg. Vizcaino), Les Lanes Sud, Fontcouverte, Aude; G-I, Rhyncolites foncouvertensis n. sp., paratype (coll. Martinez, copie MNHN A27314), Requy, Montlaur, Aude; J-L, Rhyncolites aturensis n. sp., holotype (coll. Cluzaud, copie MNHN A27315), Abesse, Saint-Paul-lès-Dax, Landes. Abréviation: mo, traces de matière organique. Échelles: $10 \mathrm{~mm}$. 
TABlEAu 9. - Dimensions de Rhyncolites foncouvertensis n. sp. Abréviations: voir Figure 2.

\begin{tabular}{lllllllllllllll}
\hline & $\mathbf{L}$ & $\mathbf{I}$ & $\mathbf{H}$ & $\mathbf{L c}$ & $\mathbf{L h}$ & $\mathbf{l h}$ & & & & & & & \\
& $(\mathrm{mm})$ & $(\mathrm{mm})$ & $(\mathrm{mm})$ & $(\mathrm{mm})$ & $(\mathrm{mm})$ & $(\mathrm{mm})$ & $\mathbf{I} / \mathbf{L}$ & $\mathbf{H} / \mathbf{L}$ & $\mathbf{I h} / \mathbf{l}$ & $\mathbf{L h} / \mathbf{L c}$ & $\alpha$ & $\beta$ & $\gamma$ & $\delta$ \\
\hline Holotype & 15,4 & 8,2 & 8 & 15,5 & 9 & 5,8 & 0,53 & 0,51 & 0,63 & 0,58 & $54^{\circ}$ & $60^{\circ}$ & $30^{\circ}$ & $102^{\circ}$ \\
Paratype & 14,5 & 8 & 6,5 & 10 & 7 & 5,1 & 0,55 & 0,44 & 0,63 & 0,70 & $69^{\circ}$ & $73^{\circ}$ & $48^{\circ}$ & $110^{\circ}$ \\
\hline
\end{tabular}

au niveau de l'apex et au niveau des parties latérales concaves du capuchon, elle présente au-delà, une forte convexité. Elle s'atténue à mi-longueur de la hampe, bien avant d'atteindre l'extrémité postérieure. Les bords de la hampe sont fortement surélevés et tranchants. La surface ventrale de la hampe, au-delà de l'arête médiane, est lisse et aplatie. Dans la zone des points latéro-antérieurs internes, sous les bords latéro-postérieurs, la hampe du paratype no 3 montre des traces importantes de matière organique sombre et correspondant à l'insertion des feuilles conchiolinitiques de la mandibule supérieure.

\section{REMARQUES}

Le rhyncholite le plus similaire à Rhyncolites corbaricus $\mathrm{n}$. sp. est $R$. vilcassinus $\mathrm{n}$. sp. du Lutétien du Bassin de Paris comme nous l'avons écrit dans la description de ce dernier. L'espèce des Corbières en diffère toutefois par une arête médiane présentant une partie convexe beaucoup plus saillante, sans élévation au niveau de l'apex et s'atténuant rapidement sans atteindre le point postérieur de la hampe. On peut relever également l'absence de sillons sur la face ventrale. Rhyncolites oppenheimi de l'Éocène d'Égypte (Afrique), autre grand rhyncholite, en diffère par des dimensions plus importantes (44 mm), par une hampe beaucoup plus longue, par une arête médiane présentant une protubérance, par un capuchon plus court en arrière et un contour des bords latéro-antérieurs encore plus nettement concave.

\section{Rhyncolites foncouvertensis $\mathrm{n}$. $\mathrm{sp}$.}

(Figs 9D-I; 12)

Rhyncolite [sic] sp. 2 - Martinez 1998: 6, pl. 1, fig. 3a-d.

Matériel TYPe. - Holotype (MNHN A27254, leg. Vizcaino). Paratype (coll. Martinez, copie MNHN A27314) de Requy, Montlaur (Aude).
ÉTYMologie. - De sa localité type.

Localité TyPe. - Les Lanes Sud, Foncouverte (Aude).

ÉTAGE TYPE. - Ilerdien (Yprésien, Éocène inférieur).

Dimensions. - Voir Tableau 9.

\section{DESCRIPTION}

Le capuchon est particulièrement développé en longueur, de forme sub-rhomboédrique, élancé et présente un apex très pointu. La hampe est haute et très courte. Étroite dans sa partie médiane, elle est élargie dans sa partie postérieure. La face dorsale du capuchon est partagée en deux parties égales par une crête médiane antérieure bien marquée et terminé par un vertex aigu. Sa surface est marquée de nombreuses stries parallèles. Les bords latéro-antérieur et latéro-postérieur sont tranchants. Les bords latéro-antérieurs présentent un contour concave très important, accentuant l'apex. La crête médiane postérieure de la hampe est à peine soulignée et fuyante. Les crêtes latérales postérieures présentent une angulosité bien marquée. Les flancs de la hampe dans la zone des points latéro-antérieurs internes sont légèrement concaves. La face ventrale est marquée par une arête médiane saillante et anguleuse, peu élevée au niveau de l'apex et au niveau des parties latérales concaves du capuchon, elle présente au-delà, une forte convexité. Elle s'atténue à mi-longueur de la hampe, bien avant d'atteindre l'extrémité postérieure. La surface ventrale du capuchon présente une concavité importante. La surface ventrale de la hampe est lisse de chaque côté de l'arête médiane.

REMARQUES

Rhyncolites foncouvertensis n. sp. diffère des rhyncholites éocènes étudiés par son apex élancé et pointu, par l'allongement de son capuchon pré- 


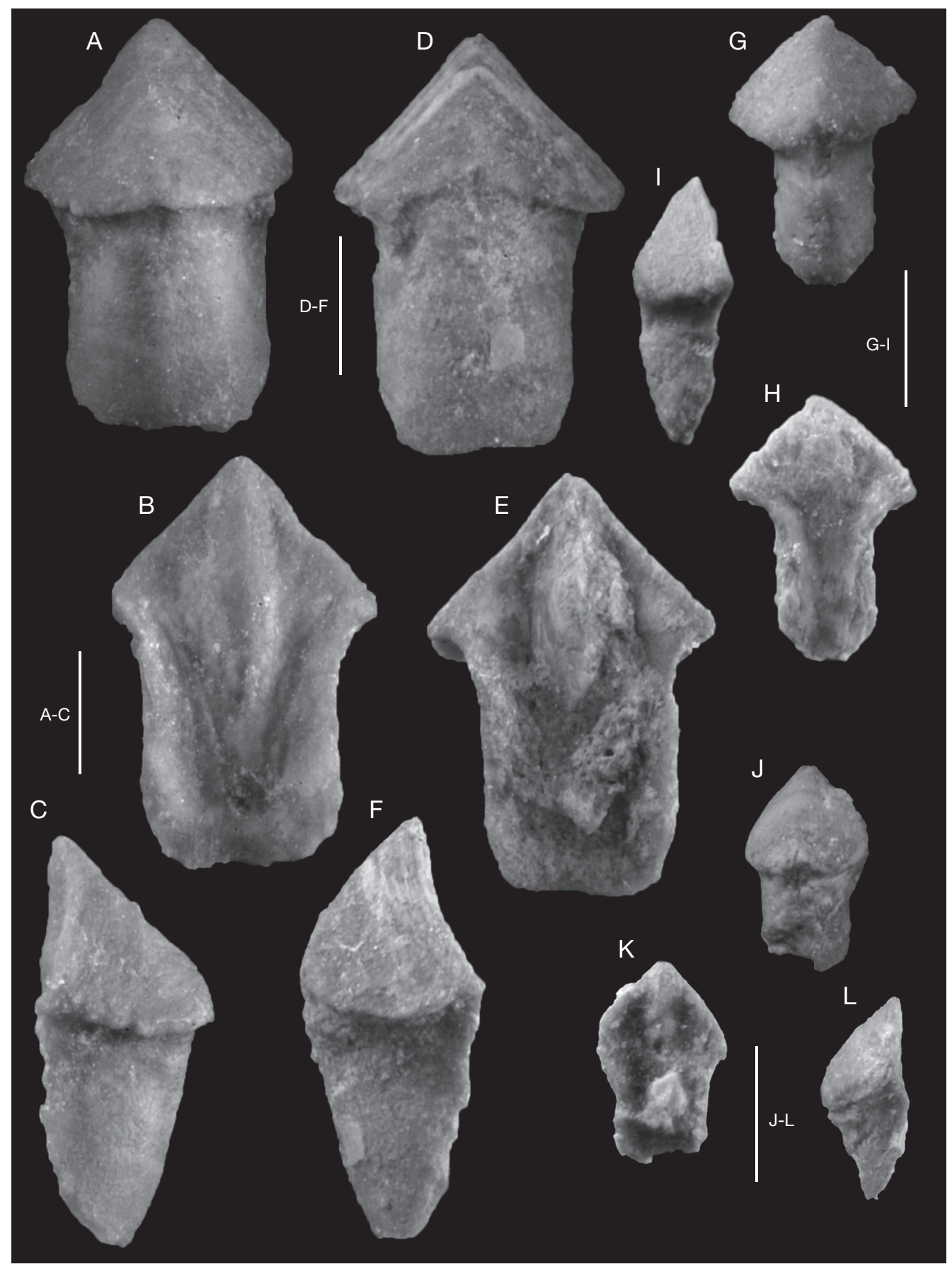

Fig. 10. - Rhyncolites martinezi n. sp., Requy, Montlaur, Aude: A-C, holotype (coll. Martinez, copie MNHN A27372); D-F, paratype $\mathrm{n}^{\circ} 1$ (coll. Martinez, copie MNHN A27373); G-I, paratype $\mathrm{n}^{\circ} 2$ (coll. Martinez); J-L, paratype $\mathrm{n}^{\circ} 3$ (coll. Martinez). Échelles: $1 \mathrm{~mm}$. 
TABLEAU 10. - Dimensions de Rhyncolites martinezi n. sp. Abréviations: voir Figure 2.

\begin{tabular}{|c|c|c|c|c|c|c|c|c|c|c|c|c|c|c|}
\hline & $\underset{(\mathrm{mm})}{\mathbf{L}}$ & $\begin{array}{c}\text { I } \\
(\mathrm{mm})\end{array}$ & $\underset{(\mathrm{mm})}{\mathbf{H}}$ & $\begin{array}{l}\text { Lc } \\
(\mathrm{mm})\end{array}$ & $\begin{array}{c}\text { Lh } \\
(\mathrm{mm})\end{array}$ & $\begin{array}{c}\mathbf{l h} \\
(\mathrm{mm})\end{array}$ & I/L & $H / L$ & Ih/I & Lh/Lc & $\alpha$ & $\beta$ & $\gamma$ & $\delta$ \\
\hline Holotype & 3 & 2 & 1 & 2 & 1 & 1,8 & 3 & 39 & 0,80 & 0,9 & $83^{\circ}$ & $96^{\circ}$ & $50^{\circ}$ & $120^{\circ}$ \\
\hline Parat) & 3 & 2 & 1 & 1, & & & 0,66 & 0,40 & 0,75 & 1,26 & $84^{\circ}$ & $120^{\circ}$ & $5^{\circ}$ & $130^{\circ}$ \\
\hline Parat & $2, \varepsilon$ & 1,8 & 1 , & 1,8 & 1, & & 0,64 & 0,42 & 0,83 & 1 & $83^{\circ}$ & $92^{\circ}$ & $3^{\circ}$ & $118^{\circ}$ \\
\hline Para & 2 & 1,4 & 0 & 1 & 1, & 0,7 & 0,70 & 0,35 & 0,50 & 1,2 & $96^{\circ}$ & $108^{\circ}$ & $53^{\circ}$ & $135^{\circ}$ \\
\hline Paratype 4 & 1,5 & 0,9 & 0,7 & 1 & 0,8 & 0,5 & 0,60 & 0,46 & 0,55 & 0,8 & $71^{\circ}$ & $100^{\circ}$ & $45^{\circ}$ & $115^{\circ}$ \\
\hline
\end{tabular}

sentant une adaptation extrême au déchirement des proies et par sa hampe très courte. Rhyncolites shinfieldensis et $R$. aethioparion diffèrent de cette espèce par leurs dimensions réduites, par la présence de la protubérance de l'arête médiane de la face ventrale totalement absente chez $R$. foncouvertensis n. sp. Rhyncolites sagittarius $\mathrm{n}$. sp. en diffère par la présence de la callosité de la hampe à la base du vertex. Rhyncolites vilcassinus n. sp. et $R$. corbaricus $\mathrm{n}$. sp. en diffèrent par leur capuchon moins allongé, à l'apex moins aigu, par un contour des bords latéro-antérieurs plus concave et par leur arête médiane ventrale de section arrondie.

Rhyncolites martinezi $\mathrm{n}$. sp.

(Figs 10;12)

MatéRIEL TYPe. - Holotype (coll. Martinez, copie MNHN A27372). Paratypes, 4 exemplaires: spécimen $\mathrm{n}^{\circ} 1$ (coll. Martinez, copie MNHN A27373), spécimens no 2-4 (coll. Martinez).

ÉTYMologie. - Dédié à Alain Martinez qui a récolté le matériel.

Localité type. - Requy, Montlaur (Aude).

ÉTAGE TYPE. - Ilerdien (Yprésien, Éocène inférieur).

Dimensions. - Voir Tableau 10.

\section{DESCRIPTION}

Rhyncholite de taille relativement réduite. Le capuchon est peu développé de forme triangulaire et à l'apex bien marqué et pointu. La hampe est courte et large sur toute sa longueur. La face dorsale du capuchon est partagée en deux parties égales par une crête médiane antérieure largement arrondie. Les bords latéro-antérieur et latéro-postérieur sont tranchants et concaves. Les bords latéro-antérieurs présentent un contour nettement concave, accentuant l'apex. L'extrémité des bords latéro-antérieurs est pointue. La crête médiane postérieure de la hampe est à peine perceptible. Les crêtes latérales postérieures, mieux marquées, présentent une angulosité à peine soulignée. Les flancs de la hampe, dans la zone des points latéro-antérieurs internes sont légèrement concaves, accentuant les crêtes latérales postérieures. La face ventrale est marquée par une arête médiane saillante, assez élevée au niveau de l'apex. Elle présente dans la zone des parties latérales concaves, un épaississement formant une protubérance. Elle s'abaisse ensuite, puis s'atténue juste avant d'atteindre l'extrémité postérieure. Les bords de la hampe sont fortement surélevés et tranchants.

\section{REMARQUES}

Rhyncolites martinezi n. sp. diffère des autres rhyncholites éocènes étudiés par sa taille particulièrement réduite. Le rhyncholite le plus similaire est $R$. lhommei n. sp. du Lutétien du bassin de Paris. L'espèce du Lutétien diffère cependant de $R$. martinezi n. sp. par une hampe plus basse, nettement aplatie et creusée d'un sillon dorsal. Elle est conique, plus étroite vers le point postérieur, aux flancs plus concaves et aux bords non surélevés. Son arête médiane est moins large. Les bords latéro-antérieurs présentent également un contour nettement moins concave. Rhyncolites sp. Teichert \& Stanley 1975 de l'Éocène d'Ardath Shale (Californie) en diffère par son capuchon de forme rhomboédrique, par les flancs de la hampe, linéaire sur toute la longueur et par une arête médiane de la face ventrale sans protubérance. 


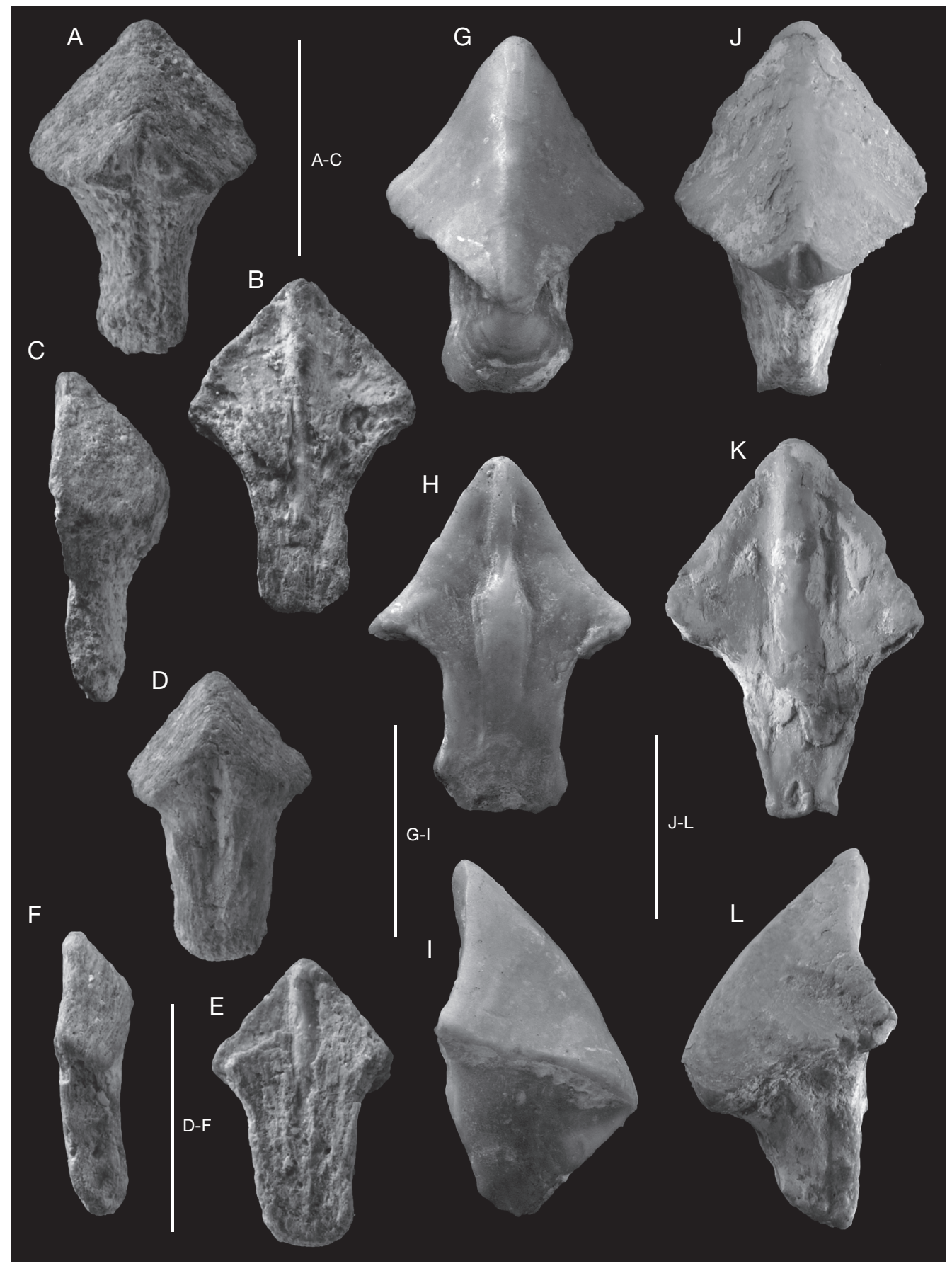

FIG. 11. - A-F, Rhyncolites Ihommei n. sp.; A-C, holotype, MNHN A27223 (leg. Lhomme), Champagne-sur-Oise (Val d'Oise); D-F, paratype, MNHN A27224 (leg. Lhomme), Champagne-sur-Oise (Val d'Oise); G-I, Rhyncolites erroitegiensis n. sp., holotype MNHN A27257 (leg. Vizcaino), Roitegui, Arraia-Maeztu, Espagne; J-L, Rhyncolites dutemplei (d'Orbigny, 1847), holotype MNHN B16881 (coll. d'Orbigny), Chavot, Marne. Échelles: A-F, 5 mm; G-L, 10 mm. 
TABlEAU 11. - Dimensions de Rhyncolites sp. Abréviations: voir Figure 2.

\begin{tabular}{cccccccccccccccc}
\hline & $\mathbf{L}$ & $\mathbf{I}$ & $\mathbf{H}$ & $\mathbf{L c}$ & $\mathbf{L h}$ & $\mathbf{l h}$ \\
$(\mathrm{mm})$ & $(\mathrm{mm})$ & $(\mathrm{mm})$ & $(\mathrm{mm})$ & $(\mathrm{mm})$ & $(\mathrm{mm})$ & $\mathbf{I} / \mathbf{L}$ & $\mathbf{H} / \mathbf{L}$ & $\mathbf{I h} / \mathbf{I}$ & $\mathbf{L h} / \mathbf{L c}$ & $\alpha$ & $\beta$ & $\boldsymbol{\gamma}$ & $\delta$ \\
\hline Coll. Martinez & 3 & 2,8 & 1,8 & - & - & 1,8 & 0,93 & 0,60 & 0,64 & - & - & - & - & - \\
\hline
\end{tabular}

TABLEAU 12. - Dimensions de Rhyncolites guanensis n. sp. Abréviations: voir Figure 2.

\begin{tabular}{cccccccccccccccc}
\hline & $\mathbf{L}$ & $\mathbf{I}$ & $\mathbf{H}$ & $\mathbf{L c}$ & $\mathbf{L h}$ & $\mathbf{I h}$ & & & & & & \\
& $(\mathrm{mm})$ & $(\mathrm{mm})$ & $(\mathrm{mm})$ & $(\mathrm{mm})$ & $(\mathrm{mm})$ & $(\mathrm{mm})$ & $\mathbf{I} / \mathbf{L}$ & $\mathbf{H} / \mathbf{L}$ & $\mathbf{I h} / \mathbf{I}$ & $\mathbf{L h} / \mathbf{L c}$ & $\boldsymbol{\alpha}$ & $\boldsymbol{\beta}$ & $\boldsymbol{\gamma}$ & $\delta$ \\
\hline Holotype & 27 & 15,1 & 13,5 & 18,5 & 17 & 11 & 0,55 & 0,50 & 0,72 & 0,91 & $78^{\circ}$ & $100^{\circ}$ & $48^{\circ}$ & $115^{\circ}$ \\
\hline
\end{tabular}

Rhyncolites sp. (Fig. 8G, H)

Rhyncolite [sic] sp. 3 - Martinez 1998: 6, pl. 2, fig. 1a-c. MATÉRIel eXAMiné. - Un spécimen (coll. Martinez). Localité TYPe. - Le Coucou, Camplong-d'Aude (Aude).

ÉTAGE TYPE. — Ilerdien (Yprésien, Éocène inférieur).

Dimensions. — Voir Tableau 11.

\section{DisCUSSION}

Rhyncholite de taille relativement réduite. Spécimen fortement altéré et brisé en plusieurs endroits (apex et hampe). L'exemplaire montre un capuchon large, de forme sub-rhomboédrique, à angle $\beta$ de $98^{\circ}$ et une arête médiane ventrale large et saillante, de section arrondie. Ce rhyncholite se distingue des autres espèces de dimensions réduites, par son arête médiane plus importante et par son capuchon de forme rhomboédrique plus étalé, et non triangulaire. Son état de conservation ne permet pas toutefois de le décrire plus amplement et de le rapprocher d'une espèce connue.

\section{Rhyncolites guanensis n. sp.}

(Figs 9A-C; 12)

Rhyncolite [sic] sp. - Merle 1986: 44.

MATÉRIEL TYPE. - Holotype (MNHN A27253, leg. Belliard).
Autre Matériel eXAMiné. - 2 spécimens (récolte Merle) confiés à feu $\mathrm{H}$. Tintant pour étude. Matériel non retrouvé à l'Université de Dijon (examen d'après photographies).

ÉTYMologie. - De sa localité type, Gan (anciennement la bastide de Guan, fondée en 1335 par Gaston II de Foix-Béarn).

LOCALité TYPe. - La Tuilerie, Gan (Pyrénées-Atlantiques).

ÉTAGE TYPE. - Cuisien (Yprésien, Éocène inférieur).

Dimensions. - Voir Tableau 12.

\section{DESCRIPTION}

Rhyncholite de taille relativement grande. Le capuchon est bien développé, de forme sub-rhomboédrique et à l'apex bien marqué et pointu. La hampe est haute, longue et légèrement concave dans sa partie médiane, elle est élargie dans sa partie postérieure. La face dorsale du capuchon est partagée en deux parties égales par une crête médiane antérieure légèrement anguleuse. Le vertex fait saillie. La surface du capuchon est marquée de stries, nombreuses et parallèles, induites par plusieurs couches concentriques. Les bords latéro-antérieur et latéro-postérieur sont tranchants et concaves. Les bords latéro-antérieurs présentent un contour concave très important, accentuant l'apex. Sur la face ventrale, légèrement en retrait et parallèles aux bords latéro-antérieurs, on distingue également deux carènes, de courbure identique, servant semble-t-il à améliorer la prise de la nourriture. La crête médiane postérieure de la hampe est légèrement convexe et peu marquée, 
fuyante. Les crêtes latérales postérieures présentent une angulosité à peine soulignée sur la hampe. Les flancs de la hampe, dans la zone des points latéroantérieurs internes et la hampe elle-même, montrent des traces importantes de matière organique sombre, charbonneuse et correspondant à l'insertion des feuilles conchiolinitiques de la mandibule supérieure. La face ventrale est marquée par une arête médiane saillante, étroite, de section arrondie, assez élevée au niveau de l'apex, elle s'abaisse ensuite, puis présente, au-delà des parties latérales concaves du capuchon, une légère convexité. Elle s'atténue juste avant d'atteindre l'extrémité postérieure. Les bords de la hampe sont surélevés et tranchants. La surface ventrale est nettement concave et lisse de chaque côté de l'arête médiane.

\section{REMARQUES}

Par ses dimensions, $R$. guanensis n. sp. est proche de $R$. albestii Popescu Voiteşti, 1910 du Lutétien de Roumanie et de $R$. oppenheimi de l'Éocène d'Égypte. L'espèce du Béarn en diffère cependant par sa taille plus faible, par un capuchon moins développé et par une hampe plus courte. Rhyncolites vilcassinus $\mathrm{n}$. $\mathrm{sp}$. est également une forme très proche; $R$. guanensis n. sp. en diffère par une arête médiane de la face ventrale moins épaisse, présentant une protubérance, par l'absence de sillons sur la face ventrale et par une courbure des bords latéro-antérieurs plus importante. Rhyncolites sagittarius n. sp. présente une callosité du vertex. Rhyncolites corbaricus $n$. sp. en diffère par une hampe plus étroite dans sa partie médiane, par une arête médiane présentant une partie convexe beaucoup plus saillante, sans protubérance et qui s'atténue plus rapidement. Rhyncolites shinfieldensis et $R$. aethioparion, qui présentent une protubérance de l'arête médiane, sont des espèces de petites tailles et diffèrent radicalement de $R$. guanensis n. sp.

\section{Rhyncolites aturensis $\mathrm{n} . \mathrm{sp}$.}

(Figs 9J-L; 12)

Matériel tyPe. - Holotype (coll. Cluzaud, copie MNHN A27315).

ÉtYMologie. - Du bassin de l'Adour, sa région type.

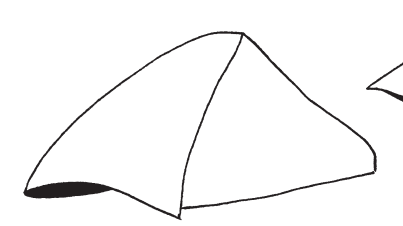

R. vilcassinus $\mathrm{n}$. $\mathrm{sp}$.
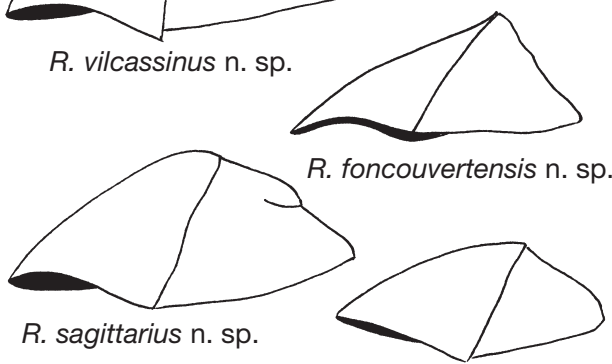

R. shinfieldensis
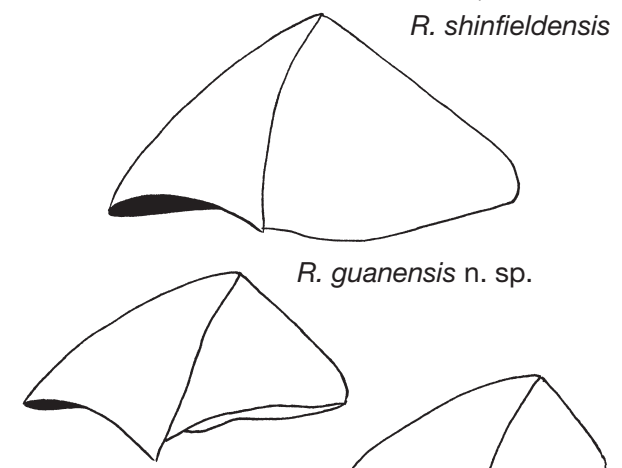

R. guanensis n. sp.

$R$. corbaricus n. sp.

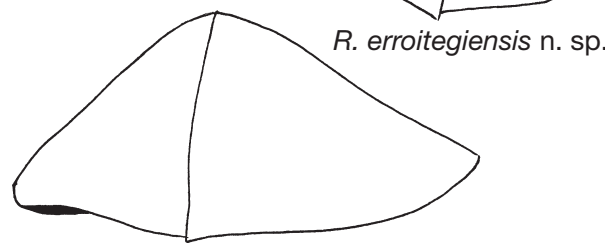

R. aturensis n. sp.

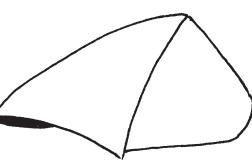

$R$. erroitegiensis $\mathrm{n} . \mathrm{sp}$.

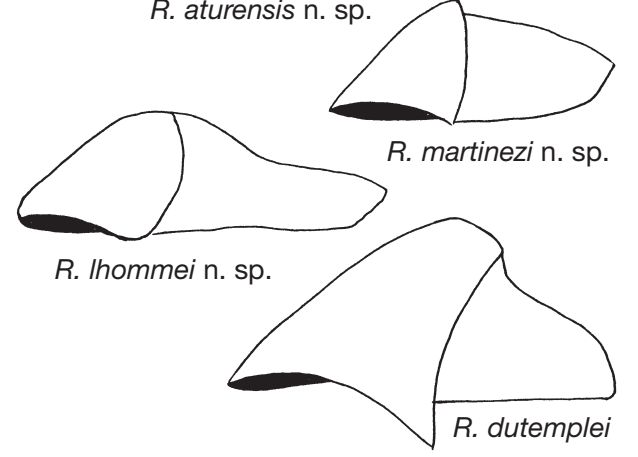

FIG. 12. - Aspect des rhyncholites étudiés en vue latérale. La surface noire représente l'arête médiane convexe de la surface ventrale. 
TABLEAU 13. - Dimensions de Rhyncolites aturensis n. sp. Abréviations: voir Figure 2.

\begin{tabular}{lcccccccccccccc}
\hline & $\begin{array}{c}\mathbf{L} \\
(\mathrm{mm})\end{array}$ & $\begin{array}{c}\text { I } \\
(\mathrm{mm})\end{array}$ & $\begin{array}{c}\mathbf{H} \\
(\mathrm{mm})\end{array}$ & $\begin{array}{c}\text { Lc } \\
(\mathrm{mm})\end{array}$ & $\begin{array}{c}\text { Lh } \\
(\mathrm{mm})\end{array}$ & $\begin{array}{c}\text { Ih } \\
(\mathrm{mm})\end{array}$ & $\mathbf{I} / \mathbf{L}$ & $\mathbf{H} / \mathbf{L}$ & $\mathbf{l h} / \mathbf{I}$ & $\mathbf{L h} / \mathbf{L c}$ & $\boldsymbol{\alpha}$ & $\boldsymbol{\beta}$ & $\boldsymbol{\gamma}$ & $\delta$ \\
\hline Holotype & 12,4 & 7,1 & 6,1 & 7,6 & 8,2 & 4,6 & 0,95 & 0,49 & 0,64 & 1,07 & $78^{\circ}$ & $160^{\circ}$ & $52^{\circ}$ & $108^{\circ}$ \\
\hline
\end{tabular}

Localité type. - Abesse, Saint-Paul-lès-Dax (Landes)

ÉTAGE TYPE. - Chattien (Oligocène supérieur).

Dimensions. - Voir Tableau 13.

\section{DESCRIPTION}

Le capuchon est bien développé, de forme triangulaire (angle $\beta$ de $160^{\circ}$ ) et à l'apex émoussé. La hampe est haute, déclive, longue et large sur toute sa longueur. La face dorsale du capuchon est partagée en deux parties égales par une crête médiane antérieure largement arrondie. Les bords latéroantérieur et latéro-postérieur sont tranchants et concaves. Les bords latéro-antérieurs présentent un contour légèrement concave. La crête médiane postérieure de la hampe est légèrement convexe et peu marquée, fuyante. Les crêtes latérales postérieures présentent une angulosité à peine soulignée sur la hampe. Les flancs de la hampe, dans la zone des points latéro-antérieurs internes, sont légèrement concaves. La face ventrale est marquée par une arête médiane saillante, de section arrondie, assez élevée au niveau de l'apex. Elle présente, au-delà des parties latérales concaves du capuchon, une légère convexité. Elle s'atténue au premier tiers de la longueur, au niveau des points latéro-antérieurs internes. Les bords de la hampe sont surélevés. La surface ventrale est très nettement concave et lisse de chaque côté de l'arête médiane. On distingue dans la zone des parties latérales concaves des sillons s'étendant jusqu'aux bords latéro-antérieurs.

\section{REMARQUES}

Les autres rhyncholites paléogènes possèdent des capuchons plus développés, de forme rhomboédrique. Le rhyncholite le plus proche est $R$. vilcassinus n. sp.; l'un des paratypes (spécimen no 1 ) de cette espèce montre un capuchon de forme triangulaire, à angle $\beta$ identique de $160^{\circ}$ par suite du raccour- cissement des bords latéro-postérieurs suggérant qu'il ne représente qu'une variation individuelle ou ontogénétique de $R$. vilcassinus $\mathrm{n}$. sp. Rhyncolites aturensis $\mathrm{n}$. sp. en diffère cependant par une concavité moindre de ses bords latéro-antérieurs, par une hampe plus longue, par son arête médiane plus faible qui se prolonge moins loin sur la hampe et par sa face ventrale nettement concave et lisse. Rhyncolites sagittarius n. sp., $R$. shinfieldensis et $R$. aethioparion montrent une protubérance de l'arête médiane absente chez $R$. aturensis n. sp. Rhyncolites corbaricus n. sp. en diffère par ses bords latéro-antérieurs plus concaves et par une arête médiane présentant une partie convexe beaucoup plus saillante.

\section{ANNEXE}

En annexe de cette étude nous donnons la description et des figurations de Rhyncolites dutemplei du Campanien (Crétacé supérieur) de la Marne dont nous venons de retrouver le matériel type et nous profitons de l'occasion pour décrire $R$. erroitegiensis $\mathrm{n}$. sp. du Thanétien (Paléocène supérieur) de la Communauté autonome du Pays-Basque (Espagne).

L'holotype par monotypie de l'espèce Rhynchoteuthis dutemplei d'Orbigny, 1847 du Campanien de Chavot (Marne), avait été perdu par d'Orbigny avant qu'il puisse en donner une bonne description. Toutefois et contrairement aux assertions de Dieni (1975: 48), le nom Rhynchoteuthis dutemplei ne peut être rejeté dans la mesure où, conformément à l'article $12.1 \mathrm{du}$ Code (CINZ 1999), une indication a été proposée par d'Orbigny. En effet, d'Orbigny (1847) écrit: «M. Dutemple m'avait prêté un exemplaire de bec de ce genre [Rhynchoteuthis], rencontré par lui à Chavot (Marne), dans la craie blanche de l'étage sénonien; mais il s'est perdu, je ne sais comment, le jour même de mon arrivée. Sa forme était voisine de celle du 


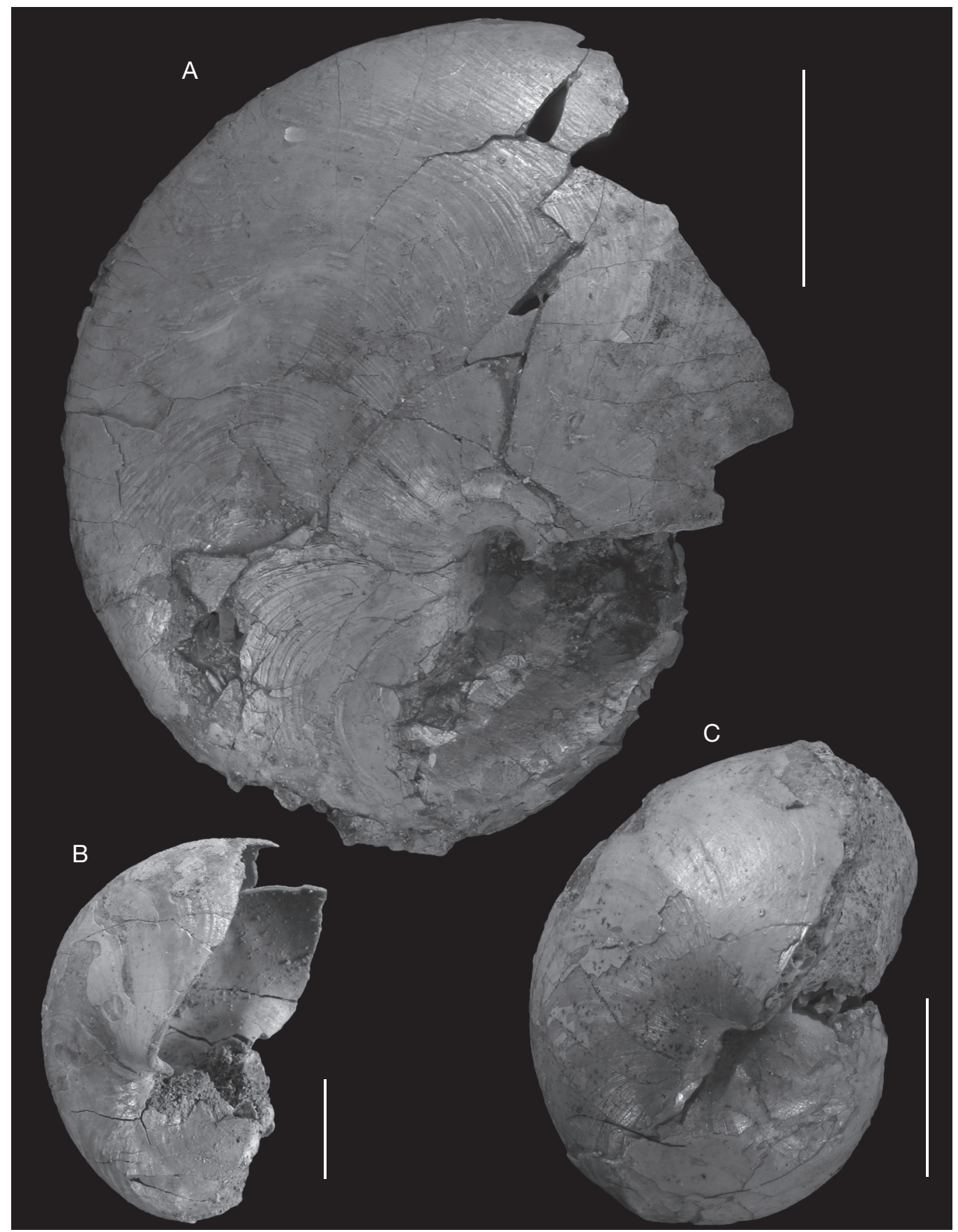

FIG. 13. - Nautiles du Paléogène du Bassin de Paris: A, Eutrephoceras parisiense (Deshayes, 1865), Yprésien (Cuisien, Éocène inférieur), Saint-Gobain (Aisne), MNHN A27244 (coll. Schtrock); B, Eutrephoceras parisiense (Deshayes, 1865), Yprésien (Cuisien, Éocène inférieur), Saint-Gobain (Aisne), MNHN A27243 (coll. Faullummel); C, Eutrephoceras umbilicare (Deshayes, 1835), Lutétien (Éocène moyen), Les Garennes, Chaussy (Val d'Oise), MNHN A27242 (coll. Schtrock). Échelles: A, 5 cm; B, 10 mm; C, 20 mm. 
TABLEAU 14. - Dimensions de Rhyncolites dutemplei (d'Orbigny, 1847). Abréviations: voir Figure 2.

\begin{tabular}{lcccccccccccccc}
\hline & $\mathbf{L}$ & $\mathbf{I}$ & $\mathbf{H}$ & $\mathbf{L c}$ & $\mathbf{L h}$ & $\mathbf{l h}$ & & & & & & & \\
$(\mathrm{mm})$ & $(\mathrm{mm})$ & $(\mathrm{mm})$ & $(\mathrm{mm})$ & $(\mathrm{mm})$ & $(\mathrm{mm})$ & $\mathbf{I} \mathbf{L}$ & $\mathbf{H} / \mathbf{L}$ & $\mathbf{l h} / \mathbf{I}$ & $\mathbf{L h} / \mathbf{L c}$ & $\boldsymbol{\alpha}$ & $\beta$ & $\boldsymbol{\gamma}$ & $\delta$ \\
\hline Holotype & 20,5 & 13,8 & 10,5 & 16 & 11,5 & 4 & 0,68 & 0,51 & 0,28 & 0,71 & $110^{\circ}$ & $110^{\circ}$ & $42^{\circ}$ & $115^{\circ}$ \\
\hline
\end{tabular}

Rhynchoteuthis emerici, mais un peu plus court. J'espère que la découverte d'autres échantillons me permettra, par la suite, de le figurer». L'exemplaire unique de cette espèce a été retrouvé dans la collection d'Orbigny, le catalogue de la collection le mentionnant au $\mathrm{n}^{\circ} 7174 \mathrm{a}$. Un second spécimen, non mentionné dans la publication, est inscrit au catalogue sous le no 7174 et provient d'Épernay (Marne); nous n'avons pas retrouvé ce spécimen. Nous sommes donc en mesure de donner une description et une figuration de cette espèce que nous rapportons non plus au Rhynchoteuthis mais au genre Rhyncolites Biguet, 1919.

\section{Rhyncolites dutemplei \\ (d'Orbigny, 1847) n. comb.}

(Figs 11J-L; 12)

Rhynchoteuthis dutemplei d'Orbigny, 1847a: 599; 1847b: 28; 1850: 211; 1855: 390. — Pictet 1854: 716. — Dieni 1975: 47, 48.

«Bec de Nautile» - Hébert 1855: 369, pl. 29, fig. 1a-c.

MATÉRIEL TYPE. - Holotype (MNHN B16881, coll. d'Orbigny).

LOCALITÉ TYPE. - Chavot (Marne).

ÉTAGE TYPE. - Campanien (Crétacé supérieur).

Dimensions. - Voir Tableau 14.

\section{DESCRIPTION}

Le capuchon est bien développé, de forme sub-rhomboédrique, à apex pointu. La hampe est basse et très courte. Large après le capuchon, elle est étroite dans sa partie postérieure. La face dorsale du capuchon est partagée en deux parties égales par une crête médiane antérieure largement arrondie. Les bords latéraux sont tranchants. Les bords latéro-antérieurs présentent un contour concave très important, accentuant l'apex. L'extrémité postérieure des bords latéro-antérieurs est fortement pointue, dépassant largement la face ventrale. La crête médiane postérieure de la hampe est fuyante, peu marquée et aplatie. Les crêtes latérales postérieures présentent une angulosité à peine soulignée. La face ventrale est marquée par une arête médiane, de section arrondie, élevée au niveau de l'apex, large et saillante jusqu'à mi longueur du capuchon, elle présente ensuite un contour nettement concave jusque vers les points latéro-antérieurs internes et enfin, avant d'atteindre l'extrémité postérieure, montre un élargissement de l'arête médiane. Les parties latérales du capuchon sont fortement concaves. La surface ventrale de la hampe est lisse de chaque côté de l'arête médiane.

\section{REMARQUES}

L'exemplaire provenant du Campanien de Meudon (Hauts-de-Seine) discuté et figuré par Hébert (1855: 369, pl. 29, fig. 1a-c) sous le nom de «Bec de Nautile» montre une parfaite identité avec Rhyncolites dutemplei. D'Orbigny identifie à tort son espèce au genre Rhynchoteuthis. Le spécimen montre une mandibule supérieure unipartite telle que celles des Rhyncolites et non pas tripartite comme chez les Rhynchoteuthis. Dès le Néocomien (Crétacé supérieur) les Rhynchoteuthis montrent de plus une régression des formes déchirante et perçante et cette espèce présente une adaptation extrême au déchirement des proies. Rhyncolites dutemplei est similaire à des espèces telles que $R$. americanus Teichet \& Spinosa, 1971 du Maastrichtien (Crétacé supérieur) de Prairie BluffChalk (Oklibbeha County, Mississippi), R. curvatus Till, 1907 du Néocomien de Schöppenstedt (Allemagne) ou de R. curtus Till, 1907 du Crétacé moyen d'Angleterre qui présentent une hampe courte, conique, plus étroite vers le point postérieur. Rhyncolites dutemplei en differe cependant par une concavité des bords latéro-antérieurs du capuchon bien plus importante, accentuant fortement la pointe de l'apex, rappelant par ses caractères $R$. giganteus d'Orbigny, 1825 (MNHN R07568) ou R. ignotus Till, 1907 (MNHN R07566) du Kimmé- 


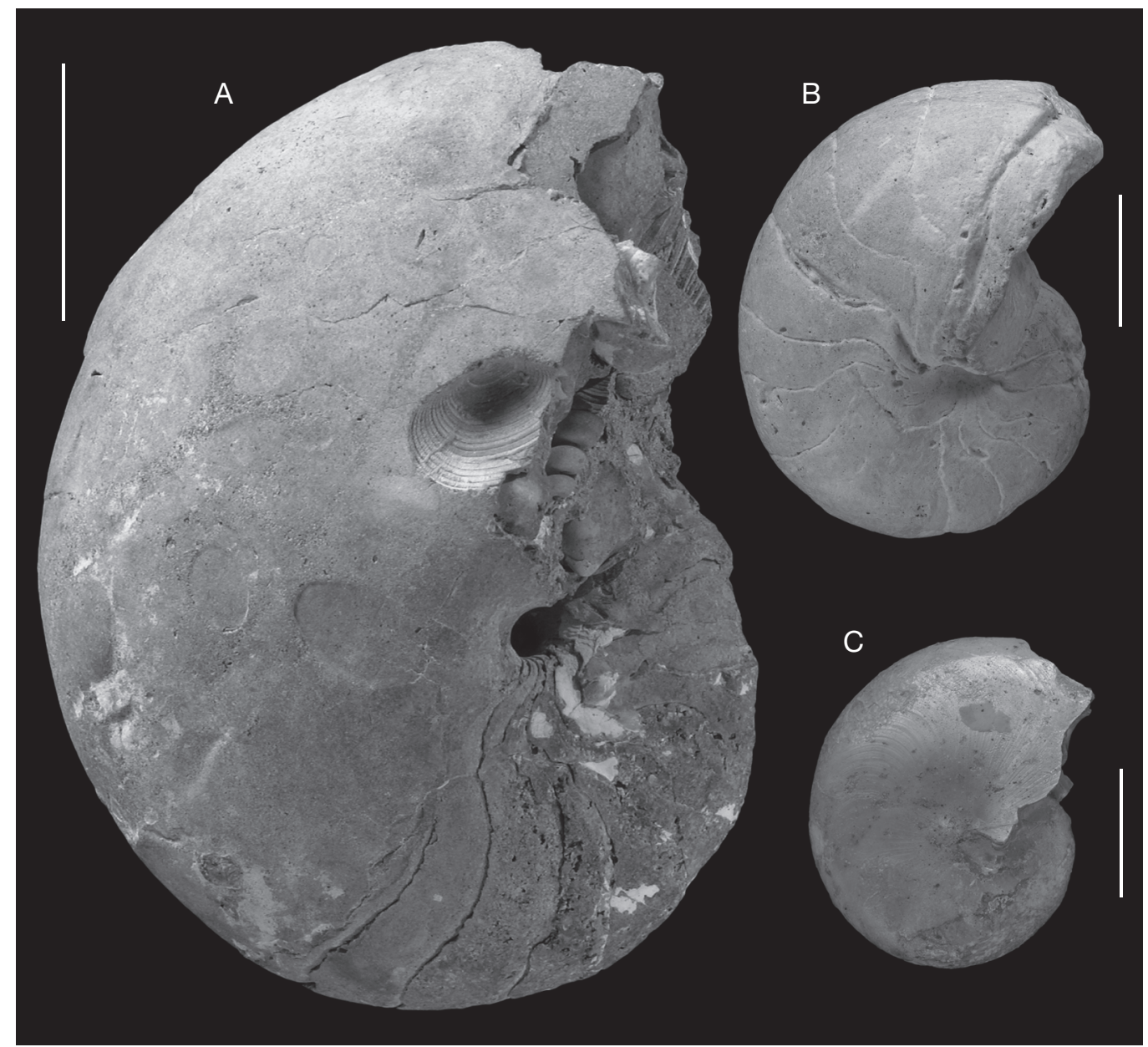

FIG. 14. - Nautiles du Paléogène du Bassin de Paris: A, Eutrephoceras umbilicare (Deshayes, 1835), Lutétien (Éocène moyen), Montde-Magny, Gisors (Eure), MNHN A27245 (leg. Pacaud); B, Eutrephoceras umbilicare (Deshayes, 1835), Lutétien (Éocène moyen), Mont-de-Magny, Gisors (Eure), copie, MNHN A27250 (coll. Castanet); C, Aturoidea ziczac (Sowerby, 1812), Lutétien (Éocène moyen), Chaumont-en-Vexin (Oise), MNHN A27247 (coll. Schtrock). Échelles: A, 5 cm; B, 20 mm; C, 10 mm.

ridgien (Jurassique supérieur) de la pointe du Chay, Angoulins (Charente-Maritime, France), des formes présentant une adaptation extrême au déchirement des proies.

\section{Rhyncolites erroitegiensis $\mathrm{n}$. $\mathrm{sp}$. (Figs 11G-I; 12)}

MATÉRIEL TYPe. - Holotype (MNHN A27257, leg. Vizcaino).
ÉTYMologie. - De sa localité type, Erroitegi en basque.

LOCALITÉ TYPE. - Roitegui, Arraia-Maeztu (Province de Álava, Communauté autonome du Pays-Basque, Espagne).

ÉTAGE TYPE. — Thanétien (Paléocène supérieur).

Dimensions. - Voir Tableau 15.

\section{DESCRIPTION}

Le capuchon est bien développé, de forme subrhomboédrique et à l'apex bien marqué et pointu. 
TABLEAU 15. - Dimensions de Rhyncolites erroitegiensis n. sp. Abréviations: voir Figure 2.

\begin{tabular}{ccccccccccccccc}
\hline & $\mathbf{L}$ & $\mathbf{I}$ & $\mathbf{H}$ & $\mathbf{L c}$ & $\mathbf{L h}$ & $\mathbf{I h}$ & & & & & & & \\
$(\mathrm{mm})$ & $(\mathrm{mm})$ & $(\mathrm{mm})$ & $(\mathrm{mm})$ & $(\mathrm{mm})$ & $(\mathrm{mm})$ & $\mathbf{I} \mathbf{L}$ & $\mathbf{H} / \mathbf{L}$ & $\mathbf{I h} / \mathbf{I}$ & $\mathbf{L h} / \mathbf{L c}$ & $\boldsymbol{\alpha}$ & $\boldsymbol{\beta}$ & $\boldsymbol{\gamma}$ & $\delta$ \\
\hline Holotype & 17 & 12,5 & 9 & 14,5 & 8,2 & 6 & 0,73 & 0,52 & 0,48 & 0,56 & $74^{\circ}$ & $100^{\circ}$ & $50^{\circ}$ & $112^{\circ}$ \\
\hline
\end{tabular}

La hampe est haute et très courte. Étroite dans sa partie médiane, elle est élargie dans sa partie postérieure. La face dorsale du capuchon est partagée en deux parties égales par une crête médiane antérieure légèrement anguleuse. Les bords latéro-antérieur et latéro-postérieur sont tranchants et concaves. Lextrémité postérieure des bords latéro-antérieurs est fortement pointue, dépassant largement la face ventrale. La crête médiane postérieure de la hampe est largement convexe et peu marquée, fuyante. Les crêtes latérales postérieures présentent une angulosité à peine soulignée sur la hampe. Les flancs de la hampe, dans la zone des points latéro-antérieurs internes, sont légèrement concaves. La face ventrale est marquée par une arête médiane saillante, de section anguleuse, assez élevée au niveau de l'apex, elle s'abaisse ensuite au niveau des parties latérales concaves du capuchon, puis présente brusquement, dans la région des points latéro-antérieurs internes, un élargissement formant ainsi une protubérance longue et légèrement convexe. Elle s'atténue avant d'atteindre l'extrémité postérieure. Les bords de la hampe sont surélevés et tranchants. La surface ventrale est très nettement concave et lisse de chaque côté de l'arête médiane. La partie postérieure de la hampe est surélevée et se termine en un talon arrondi.

\section{REMARQUES}

Rhyncolites erroitegiensis $\mathrm{n}$. sp diffère de R. vilcassinus n. sp. du Lutétien du Bassin de Paris et de $R$. corbaricus $n$. sp de l'Ilerdien des Corbières, deux espèces relativement proches, par une hampe très courte, une arête médiane de section anguleuse et non arrondie présentant une longue protubérance et non une importante convexité. On peut relever également l'absence de sillons sur la face ventrale. L'espèce basque diffère de $R$. sagittarius $\mathrm{n}$. sp. du Lutétien du Bassin de Paris, autre rhyncholite présentant une protubérance de l'arête médiane ventrale, par l'ab- sence de callosité de la hampe et par la protubérance de l'arête médiane ventrale moins importante mais plus longue. Rhyncolites aethioparion de l'Yprésien d'Angleterre et des Corbières, aux dimensions plus réduites, présente une hampe beaucoup plus large et un capuchon plus court. Rhyncolites albestii du Lutétien de Roumanie et $R$. oppenheimi de l'Éocène d'Égypte (Afrique) présentent comme chez notre rhyncholite une protubérance de l'arête médiane ventrale. Ils different toutefois de $R$. erroitegiensis n. sp. par des dimensions plus importantes, par une hampe beaucoup plus longue, par un capuchon plus court en arrière et un contour des bords latéro-antérieurs nettement concave.

\section{CONCLUSIONS ET REMARQUES}

En conclusion, la découverte de ces rhyncholites est un événement paléontologique car la connaissance des rhyncholites du Paléogène de France était jusqu’à présent nulle. Les faunes décrites ici sont entièrement nouvelles. Des spécimens importants (Thanétien d'Espagne et Campanien de la Marne) sont décrits. Actuellement, seuls les Nautiles possèdent des rhyncholites. Outre le fait que les fossiles qui nous intéressent ici se retrouvent toujours séparés des animaux auxquels ils appartiennent et que les parties conchyolinitiques des mandibules ainsi que, évidement, les parties molles ne sont jamais conservées, l'analogie avec les rhyncholites des Nautiles actuels (Teichert et al. 1964; Gasiorowski 1973a, b; Okutani \& Mikami 1977; Saunders et al. 1978) est trop évidente pour que l'on puisse douter de l'appartenance du matériel fossile. Dans de rares cas, le rhyncholite a été trouvé in situ fossilisé avec la coquille du Nautile (Foord 1891). On connaît également le cas d'un Germanonautilus bidorsatus (von Schlotheim, 1820) du Muschelkalk (Trias) d'Allemagne avec le conchorhynchus trouvé in situ 
(Klug 2001). Au Paléogène, il a été essentiellement récolté des rhyncholites et peu de conchorhynchus. Ces derniers sont seulement composés de feuillets de calcite autour de la substance cornée et sont donc moins facilement fossilisables. Les découvertes de ces rhyncholites élargissent donc leur aire de distribution géographique. Les spécimens se récoltent rarement et de façon isolée dans les sédiments paléogènes et ne formaient probablement pas des essaims comme les céphalopodes à Gonatocheilus Till, 1907 et à Leptocheilus Till, 1907 comme le suggère Till (1907). De nombreux céphalopodes vivants, tels les calmars, forment des essaims tout au long ou pendant une partie de leur vie. Ces essaims comprennent parfois des millions d'individus et sont composés d'animaux de même taille, car les plus petits sont aussitôt mangés par les autres (Gasiorowski 1973a).

Face aux neuf espèces de Nautiles présents dans les seuls sédiments yprésiens d'Angleterre (London Clay, Éocène inférieur) (Spath 1927; Ward \& Cooper 1972) il est vraisemblable que la rareté des Nautiles dans les sédiments paléogènes français peut s'expliquer par la mauvaise conservation de ces derniers. De fait, les découvertes de rhyncholites sont peu nombreuses. Nous ne voulons pas ici tirer une conclusion définitive sur une variabilité intra-spécifique éventuelle plus ou moins restreinte de ces rhyncholites. Les spécimens sont peu nombreux et il s'agit donc d'un travail essentiellement descriptif, exploratoire. Notre but est d'exposer un travail susceptible de provoquer des recherches futures (analyses de la paléobiodiversité, phylogénie, développements statistiques fondés sur les mensurations...). Les rhyncholites sont riches en points homologues (landmarks) facilement reconnaissables et il pourrait par exemple être intéressant d'envisager une future étude morphométrique telle que celle établie par Neige \& Dommergues (2002) pour les becs de Céphalopodes coléoides.

\section{Remerciements}

Mes plus sincères remerciements vont à Alain Cluzaud, Didier Dutheil, Daniel Ledon, Pascal Boucher, Jean-François Lhomme, Bernard Pattedoie, JeanLuc Marcomini, Alain Martinez, Daniel Vizcaino,
Laurent Belliard et Jean-Marie Dordonat pour le prêt du matériel qu'ils ont mis à ma disposition pour cette étude, à Pierre Lozouet (MNHN) pour le prêt des mandibules de Nautile actuel, à Philippe Loubry et à Christian Lemzaouda (MNHN) pour les photographies et l'infographie des planches, à Didier Merle (MNHN) qui a réalisé pour nous l'étude biométrique, à Frédérique Michely du Service Communication/Relations Presse de l'Aquarium de la Rochelle (Charente-Maritime) pour l'autorisation de publication de la photographie du Nautilus pompilius et à Philippe Richir et Batz Le Dimet $(\mathrm{MNHN})$ pour la réalisation des copies des Rhyncholites. Nos remerciements vont également à Jean-Louis Dommergues et à Neil Landman pour leurs judicieuses critiques du manuscrit.

\section{RÉFÉRENCES}

Bellardi L. 1873. - I Molluschi dei Terreni Terziarii del Piemonte e della Liguria. Part. 1, Cephalopoda, Pteropoda, Heteropoda, Gasteropoda (Muricidae et Tritonidae). Memorie della Reale Accademia delle Scienze di Torino 2 (27): 33-294.

Biguet F. 1819. - Considérations sur les Belemnites, suivies d'un essai de belemnitologie synoptique. Kindelem, Lyon, 63 p.

Blainville M.H. Ducrotay De 1827. - Mémoire sur les Belemnites, Supplément. Levrault, Paris, 136 p.

CINZ 1999. - Code international de nomenclature zoologique (4e édition). International Trust for Zoological Nomenclature, Londres, v-xxix $+306 \mathrm{p}$.

Clarke M. R. 1962. - The identification of Cephalopod "beaks" and the relationship between beak size and total body weight. Bulletin of British Museum (Natural History), Zoology 8 (10): 419-480.

Clarke M. R. 1986. - A Handbook for the Identification of Cephalopod Beaks. Clarendon Press, Oxford, $273 \mathrm{p}$.

Closs D. 1967. — Goniatiten mit Radula und Kierferapparat in der Itararé-Formation von Uruguay. Paläontologische Zeitschrift 41 (1-2): 19-36.

Cossmann M. 1892. — Catalogue illustré des coquilles fossiles de l'Éocène des Environs de Paris. 5e Fascicule et supplément. Annales de la Société royale malacologique de Belgique 26: 7-167, pl. 1-3.

CrICK G. C. 1916. - Note on a gigantic cephalopod mandible. Geological Magazine 3: 260-264.

Dean B. 1901. - Note on living Nautilus. American Naturalist 35: 818-837.

DeshaYes G.-P. 1835. - Description des coquilles fossiles 
des environs de Paris. Tome 2, livraisons 40-45, Levrault, Paris, p. 495-780. Atlas 2, pls 79-106.

DiENI I. 1975. - Revisione di alcune species Giurassiche e Cretacee di Rincoliti. Paleontographia Italica 69 (39): 39-107.

Doncieux L. 1908. - Catalogue descriptif des fossiles nummulitiques de l'Aude et de l'Hérault. Deuxième partie (fascicule 1): Corbières septentrionales. Annales de l'Université de Lyon 22: 1-250.

ÉLOUARD P. 1962. — Étude géologique et hydrologique des formations sédimentaires du Guébla mauritanien et de la vallée du Sénégal. Mémoires du Bureau de Recherches géologiques et minières 7: 1-274.

Foord A. H. 1891. - Catalogue of the fossil Cephalopoda in the British Museum (National History). Part 2, Nautiloides, Longmans \& Co, London, 399 p.

GAILlaRdot C. A. 1824. — Sur les becs de Sèches fossiles. Extrait d'une lettre adressée à M. Alexandre Brongniart. Annales des Sciences naturelles 2: 485-489.

GASIOROWSKI S. M. 1968. - Palaeogeographical distribution of Mesozoic rhyncholites. Bulletin de l'Académie polonaise des Sciences 16 (1): 17-20.

GASIOROWSKI S. M. 1973a. — Les Rhyncholites. Geobios $6(2): 127-196$.

GASIOROWSKI S. M. 1973b. — Les Rhyncholites (suite). Geobios 6 (3): 163-197.

GLiberT M. 1933. - Monographie de la faune malacologique du Bruxellien des environs de Bruxelles. Mémoires du Musée royal d'Histoire naturelle de Belgique 53: 1-214.

GRAY J. E. 1849. - Catalogue of the Mollusca in the Collection of the British Museum. Part. 1: Cephalopoda antepedia. Spottiswood \& Shaw, Londres, 164 p.

GrifFIN L. E. 1900. — The anatomy of Nautilus pompilius. Memories of Natural Academy of Sciences 8 (5): 100-230.

HÉBERT E. 1855. - Tableau des fossiles de la craie de Meudon et description de quelques espèces nouvelles. Mémoires de la Société géologique de France 5 (2): 345-374.

HoušA V. 1969. — Neocomian rhyncholites from Cuba. Journal of Paleontology 43 (1): 119-124.

KANIE Y. 1998. - New Vampyromorph (Coleoidea: Cephalopoda) jaw apparatuses from the late Cretaceous of Japan. Bulletin of Gunma Museum of Natural History 2: 23-34.

Kanie Y., Tanabe K., FukUda Y., Irano H. \& Obata I. 1978. - [Preliminary study of jaw apparatus in some late Cretaceous ammonites from Japan and Sakhalin]. Journal of the Geological Society of Japan 84: 629-631 (en japonais).

Kaiser P. \& Lehmann U. 1971. — Vergleichende Studien zur Evolution des Kieferapparates rezenter und fossiler Cephalopoden. Paläontologische Zeitschrift 45 (1-2): 18-32.

KLUG C. 2001. - Functional morphology and tapho- nomy of nautiloid beaks from the Middle Triassic of southern Germany. Acta Palaeontologica Polonica 46 (1): 43-68.

LANDMAN N. H. \& Cochran J. K. 1987. - Growth and longevity of Nautilus, in SAUNDERS W. B. \& LaNdman N. H. (eds), The Biology and Paleobiology of a Living Fossil. Plemum Press, New York, Londres: 401-420.

Lehmann U., Tanabe R., Kanie Y. \& FukUda Y. 1980. — Über der Kieferapparat der Lytoceratacea (Ammonoidea). Paläontologische Zeitschrift 54: 319-329.

Le Renard J. \& Pacaud J.-M. 1995. - Révision des Mollusques paléogènes du Bassin de Paris. II. Liste des références primaires des espèces. Cossmanniana 3 (3): 65-132.

Lossel P. 1947. - A propos de mâchoires de Céphalopodes fossiles dites «en bec de perroquet». Comptes rendus sommaires des Séances de la Société géologique de France 14: 280-282.

MANGOLD K. 1966. - Sepia officinalis de la Mer catalane. Vie et Milieu 17 (2A): 961-1012.

MANGOld K. \& Fioroni P. 1966. - Morphologie et biométrie des mandibules de quelques céphalopodes méditerranéens. Vie et Milieu 17 (3A): 1139-1196.

Martinez A. 1998. - Rhyncholites de l'Éocène des Corbières. Association culturelle, archéologique et paléontologique, Musée de Cruzy, Cruzy, 9 p.

Merle D. 1986. - Contribution à l'étude paléontologique du gisement de Gan (Pyrénées-Atlantiques): Systématique, évolution et paléoécologie. Diplôme de l'E.P.H.E., Paris, 394 p.

Müller A. H. 1963. — Über die Kieferapparat fossiler und rezenter Nautilida (Cephalopoda) mit Bemerkungen zur Ökologie, Funktionsweise und Phylogenie. Freiberger Forschungshefte C 298: 7-17.

MÜller A. H. 1974. - Über Rhyncholithen aus dem Oberen Muschelkalk des germanischen Triasbeckens. Geologie 12: 842-857.

Neige P. \& Dommergues J.-L. 2002. - Disparity of beaks and statoliths of some coleoids : a morphometric approach to depict shape differenciation. Abhandlungen der Geologischen Bundesanstalt 57: 393-399.

NiXON M. 1996. - Morphology of the jaws and radula in Ammonoids, in Landman N. H., TANabe K. \& Davis R. A. (eds), Ammonoid Paleobiology. Topics in Geobiology 13: 23-42.

NYsT P.-H. 1845. - Description des coquilles et des Polypiers fossiles des terrains tertiaires de la Belgique, en réponse à la question suivante: faire la description des coquilles et des Polypiers fossiles des terrains tertiaires de la Belgique, et donner l'indication précise des localités et des systèmes de roches dans lesquels ils se trouvent. Hayez, Bruxelles, 697 p.

OKUTANI T. \& MiKAMI S. 1977. - Description on beaks of Nautilus macromphalus Sowerby. Japanese Journal of Malacology 36: 115-121. 
OPPENHeim P. 1906. — Zur Kenntnis alttertiärer Faunen in Ägypten. Lieferung 2. Der Bivalven zweiter Teil; Gastropoda und Cephalopoda. Palaeontographica 30 (3): 165-348.

Orbigny A. D' 1825a. - Notice sur les becs de céphalopodes fossiles. Nouveau Bulletin des Sciences par la Société philomatique: 126.

OrbignY A. D' 1825b. - Notice sur les becs de céphalopodes fossiles. Annales des Sciences naturelles 5: 211221.

OrbignY A. D' 1826. - Tableau méthodique de la classe des céphalopodes. Annales des Sciences naturelles 57: 96-169.

OrbIGNY A. D' 1847a. - Mollusques vivants et fossiles ou description de toutes les espèces de coquilles et de Mollusques classées suivant leur distribution géologique et géographique. Gide, Paris: 577-605.

Orbigny A. D' 1847b. - Paléontologie française. Description zoologique et géologique de tous les Animaux mollusques et rayonnés fossiles de France comprenant leur application à la reconnaissance des couches. Terrains crétacés, Supplément. Arthus Bertrand, Paris, 28 p. (volume inachevé).

Orbigny A. D' 1850. - Prodrome de Paléontologie stratigraphique universelle des Animaux mollusques et rayonnés. Vol. 2. Masson, Paris, 428 p.

Orbigny A. D' 1855. - Paléontologie des coquilles et des Mollusques. Delahays, Paris, 392 p.

Owen R. 1832. - Memoir on the Pearly Nautilus (Nautilus pompilius, Linn.) with Illustrations of its External Form and Internal Structure. Richard Taylor, Londres, $68 \mathrm{p}$.

Pacaud J.-M. 2008. - Le contenu paléontologique du Lutétien du bassin de Paris: Mollusca-Brachiopoda, in Merle D. (ed.), Stratotype Lutétien. Collection Patrimoine géologique. MNHN, Paris; Biotope, Mèze; BRGM, Orléans: 35, 40-95 (sur cd-rom).

Pacaud J.-M. \& Le Renard J. 1996. — Révision des mollusques paléogènes du Bassin de Paris. IV: Liste systématique actualisée. Cossmanniana 3 (4): 151-187.

Peyrot A. 1932. - Conchologie néogènique de l'Aquitaine. Tome 6 et dernier, livraison 2: Gastropodes (fin), Ptéropodes, Céphalopodes, Brachiopodes. Actes de la Société linnéenne de Bordeaux 84: 295-541.

Philippe M. \& Granier J. 1981. — Premières découvertes de rhyncholites (Cephalopoda) dans le Miocène du Bassin du Rhône (Sud-Est de la France) et interprétations. Bulletin de la Société d'Études des Sciences naturelles du Vaucluse 1979-1981: 71-83.

PICTET F.-J. 1854. - Traité de Paléontologie ou histoire naturelle des animaux fossiles considérés dans leurs rapports zoologiques et géologiques, tome 2 . Baillière, Paris, $727 \mathrm{p}$.

POPESCU VOITEŞTI I. 1910. — Contributions à l'étude stratigraphique du Nummulitique de la dépression Gétique (Roumanie Occidentale). Anuarul Institutului
Geologic al României 3 (2a): 1-98.

SACCO F. 1904. - I Molluschi dei Terreni Terziarii del Piemonte e della Liguria. Parte 30: aggiunte e correzioni. Clausen, Torino, 203 p., 31 pls.

Saunders B., Spinosa C., Teichert C. \& Banks R. C. 1978. - The jaw apparatus of Recent Nautilus and its palaeontological implications. Palaeontology 21 (1): 129-141.

SCHLOTHEIM F. VON 1820. - Die Petrefactenkunde auf ihrem jetzigen Standpunkte durch die Beschreibung seiner Sammlung versteinerter und fossiler Überreste des Thier- und Pflanzenreichs der Vorwelt erläutert. Becker, Gotha: 437 p.

SchmidT-EfFing R. 1972. - Ein Ceratit mit KieferApparat aus dem Muschelkalk des Saarlandes. Paläontologische Zeistschrift 46 (1-2): 49-55.

SePtFontaine M. 1970. - Sur la présence des rhyncholites dans le Lias et le Dogger des Préalpes médianes romandes (Suisse). Paläontologishe Zeistschrift 44 (3-4): 103-127.

Spath L. F. 1927. - On the classification of the Tertiary Nautili. Annals of Magazine of Natural History 9 (20): 424-428.

ŞURARU N. 1963. - Asupra prezenței unor rincholite în Eocenul de la Porceşti-Sibiu [Sur la présence de rhyncholites dans l'Éocène de Porcesti-Sibiu]. Studia Universitatis Babeş-Bolyai ser. Geologica-Geographica 1: 45-50 (en roumain).

Tanabe K., Fukuda Y., Kanie Y. \& Lehmann U. 1980. Rhyncholites and Conchorhynchs as calcified jaw elements in some late Cretaceous ammonites. Lethaia 13 (2): 157-168.

Teichert C., Moore R. C. \& Zeller D. E. N. 1964. - Rhyncholites in Moore R. C. (ed.), Treatise on Invertebrate Paleontology, part K., Lawrence, Kansas: K467-K484.

Teichert C. \& Spinosa C. 1971. - Cretaceous and Tertiary Rhyncholite from the Western Atlantic Ocean and from Mississippi. The University of Kansas Paleontological Contributions 58: 1-10, pls. 1-4.

Teichert C \& Stanley G. D. 1975. - Eocene rhyncholite from California. Geology 3 (2): 178-180.

Till A. 1906. - Die Cephalopodengebisse aus dem schlesischen Neocom. Versuch einer Monographie der rhyncholiten Jahrbuch der Kaiserlich Königlichen Geologischen Reichsanstalt 56 (1): 89-154.

Till A. 1907. - Die fossilen Cephalopodengebisse. Jahrbuch der Kaiserlich Königlichen Geologischen Reichsanstalt 57 (3): 535-682.

Till A. 1909. - Die fossilen Cephalopodengebisse. Jahrbuch der Kaiserlich Königlichen Geologischen Reichsanstalt 58 (4): 573-608.

Till A. 1910. - Die fossilen Cephalopodengebisse. Jahrbuch der Kaiserlich Königlichen Geologischen Reichsanstalt 59: 407-426.

Till A. 1911. - Über einige neue rhyncholithen. 
Verhandl. der Kaiserlich Königlichen Geologischen Reichsanstalt 16: 360-365.

VALETTE A. DOM 1925. - Sur une nouvelle espèce de Céphalopode (Belosepia) de l'Helvétien supérieur. Actes de la Société linnéenne de Bordeaux 76 (2): 206-207.

VINCENT E. 1901. - Quelques mots sur les rhyncholites de l'Éocène belge. Annales de la Société royale malacologique de Belgique 35: iv-viii.

WARD D. \& COOPER J. 1972. — The first rhyncholites (Mollusca, Cephalopoda) from the English Tertiary.
Geological Association of London Proceedings 83 (4): 405-412.

Willey A. 1902. - Contribution to the Natural History of the Pearly Nautilus. In: Zoological Results Based on Material from New Britain, New Guinea, Loyalty Islands and Elsewhere, Collected During the Years 1895, 1896 and 1897. Part. 6, Cambridge University Press, Cambridge: 691-830.

ZAKHAROV Y. D. \& LOMINADZE T. A. 1983. - New data on the jaw apparatus of fossil cephalopods. Lethaia 16 (1): 67-78.

Soumis le 30 mai 2008; accepté le 27 octobre 2008. 